\title{
Microparticles \\ Novel Mechanisms of Intracellular Communication: Implication in Health and Disease
}

\author{
Anna Meiliana ${ }^{1,2 *}$ and Andi Wijaya ${ }^{1,2 *}$ \\ ${ }^{1}$ Post Graduate Program in Clinical Biochemistry, Hasanuddin University, Makassar \\ ${ }^{2}$ Prodia Clinical Laboratory, Jakarta \\ *Address correspondence to this author at: Prodia Clinical Laboratory, Jl. Cisangkuy No.2, Bandung \\ E-mail: anna_m@prodia.co.id, andi_w@prodia.co.id
}

\section{Abstract}

$\mathrm{B}$

ACKGROUND: The prevailing view that eukaryotic cells are restrained from intercellular exchange of genetic information has been challenged by recent reports on nanotubes, exosomes, apoptotic bodies, and nucleic acid-binding peptides that provide novel pathways for cell-cell communication, with implications in health and disease.

CONTENT: Microparticles (MPs) are a heterogeneous population of small plasma membrane structures that serve as important signaling structures between cells. MPs are composed of a phospholipid bilayer that exposes transmembrane proteins and receptors and encloses cytosolic components such as enzymes, transcription factors, and mRNA derived from their parent cells. Growing evidence suggests that MPs regulate inflammation, stimulate coagulation, affect vascular functions and apoptosis, and can also play a role in cell proliferation or differentiation. MPs circulate in the bloodstream, can be detected in the peripheral blood, and may originate from different vascular cell types (eg, platelets, monocytes, endothelial cells, red blood cells, and granulocytes).

SUMMARY: Cells of various types release small membrane vesicles called MP on their activation, as well as during the process of apoptosis. The properties and roles of MP generated in different contexts are diverse and are determined by their parent cell and the pathway of their generation, which affects their content. MP are involved in multiple cellular functions, including immunomodulation, inflammation, coagulation, and intercellularcommunication. MPs are able to deliver molecular signals in the form of lipids, proteins, nucleic acids, or functional trans-membrane proteins from the parent cell to distantly located targets. From a clinical point of view, MP may serve as biomarkers for disease status and may be found useful for developing novel therapeutic strategies.

KEYWORDS: Microparticles, Microvesicle, Membrane Remodeling, Intercellular communication.

Indones Biomed J 2011; 3(1): 18-36

\section{Introduction}

Cells communicate and exchange information by different mechanisms. They may communicate by (i) secreted growth factors, cytokines, chemokines and small molecular mediators (e.g., nucleotides, nitric oxide ions, bioactive lipids), (ii) cell-to-cell adhesion contacts that are mediated by sets of specialized adhesion molecules and (iii) exchanging information by means of tunneling nanotubules (1-6). However, attention is now being focused on cell-to-cell communication that involves circular membrane fragments called microparticle (MP) (7-12), a mechanism that for many years has been largely overlooked. 
It is well established that virtually all eukaryotic cells possess the fundamental capacity to release small vesicles, generally referred to as MPs. Existence of MPs, which allow a selective and concentrated release of the cellular content into the surrounding milieu, was first noticed by Wolf in 1967 as formation of a procoagulant "dust" around activated blood platelets (13). Although MPs are present in peripheral blood of healthy individuals, with platelet MPs being the most abundant and representing $70 \%$ to $90 \%$ of all circulating MPs $(14,15)$ marked elevations occur in many disease states. These conditions include autoimmune disorders, atherosclerosis, malignancies, and infection among others (14,16-18).

Shedding of membrane-derived MP is a physiological phenomenon that accompanies cell activation and growth $(7-12,15,19)$. Interestingly, rapidly growing cell lines tend to secrete more MP than slowly growing ones. Generally, the number of MP shed from cells increases upon (i) cell activation, (ii) hypoxia or irradiation, (iii) oxidative injury, (iv) exposure to proteins from an activated complement cascade and (v) exposure to shearing stress $(7-12,15,19)$. MP shedding depends on an increase in cytosolic $\mathrm{Ca}^{2+}$ and degradation of the membrane skeleton.

Although a precise definition of MPs remains elusive, they are commonly described as a heterogeneous population of spherical structures with a diameter of 100 to $1000 \mathrm{~nm}$, which are released by budding of the plasma membrane (ectocytosis) as phospholipid vesicles known to express antigens specific of their parental cells. This characterization allows differentiation from exosomes, referring to preformed vesicles with are diameter of less than $100 \mathrm{~nm}$ that are stored intracellularly in multivesicular compartments and are secreted when these endosomal compartments fuse with the cell plasma membrane $(20,21)$. Continuing efforts in deciphering the signature of circulating MPs could also lead to the development of new diagnostic strategies, with MPs emerging as unique potential sources of disease-related and possibly predictive biomarkers (22).

\section{Microparticle (MP)}

In multicellular organisms, homeostasis results from a subtle balance between cell proliferation and degenerescence. Cells differentiate, expand, fulfill particular functions, then undergo programmed death and are finally cleared by phagocytosis. At each stage of its life, the cell is subjected to a variety of stimulations leading to the release of submicron fragments from the plasma membrane, usually termed microvesicles or microparticles (MPs). MPs hijack membrane constituents and cytoplasmic content and survive the cell (10).

MPs are fragments shed almost spontaneously from the plasma membrane blebs of virtually all cell types when submitted to a number of stress conditions, including apoptosis. MP release is an integral part of the membraneremodeling process in which the asymmetric distribution of constitutive phospholipids (PL) between the two leaflets is lost. After having long been considered 'cell dust', MPs have more recently been shown to reflect in vitro cell stimulation, and testify to cellular activation and/ or tissue degeneration occurring in vivo under a variety of pathophysiologic circumstances. Besides their marker characteristics, MPs have been identified as true vectors in the transcellular exchange of biologic information (23).

On one hand, deleterious MP stemming from activated cells can elicit an adverse response from other cells, themselves undergoing membrane vesiculation, leading to pathogenic amplification. On the other hand, since they are thought to reflect a balance between cell stimulation, proliferation, and death, it is conceivable that they are discerned as sensors for the maintenance of homeostasis in multicellular organisms. Because vesiculation is an integral part of the plasma-membrane remodeling process, with the transverse migration of procoagulant phosphatidylserine from the cytoplasmic to the exoplasmic leaflet as the central event, the majority of released MPs are thought to fulfill a hemostatic function under physiologic conditions. This is particularly true when they originate from platelets, with possible deviation towards thrombosis when produced in excess (23).

It has been postulated that the phenotype of stem cells is reversibly changing during the cell cycle transit until a terminal-differentiating stimulus is encountered at a cyclesusceptible time. In this model the cell cycle status and the microenvironmental exposure to the products of contiguous cells may play key roles in stem cell plasticity (29). The same stem cell may show different phenotypes in different functional states, depending on the cell cycle phase. This dynamic context is regulated by the microenvironment and in particular the MP-mediated transfer of genetic information between cells (30).

Transfer of genetic information from injured cells may explain stem cell functional and phenotypic changes without the need for trans-differentiation into tissue cells. On the contrary, transfer of genetic information from stem cells may redirect altered functions in target cells suggesting that stem cells may repair damaged tissues without directly replacing parenchymal cells (26). MPs 


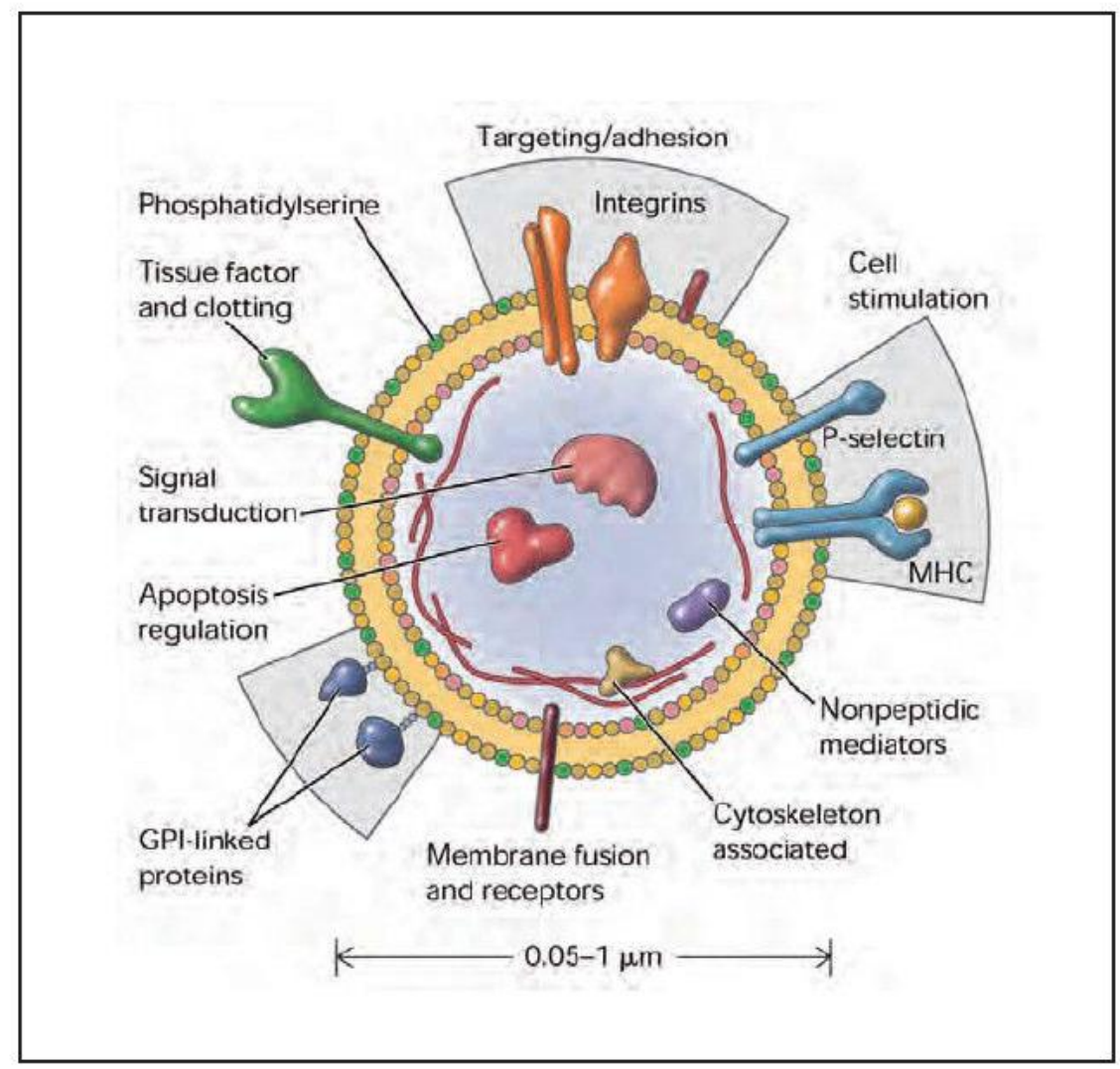

Figure 1. Cellular MP: a disseminated storage pool of bioactive effctors (Adapted with permission from American Physiol Society).

can therefore be considered a disseminated storage pool of bioactive effectors, the nature and proportion of the latter accounting for duality, more particularly evidenced in vascular disease, inflammation, and immunity (10).

Thus, MPs are vesicles that bud off from cells, lack a nucleus, contain a membrane skeleton and are defined by their size and expression on their surface of antigens specific of parental cells (27-29). These phospholipid vesicles are less than $1 \mu \mathrm{m}$ of diameter. To reliably define MPs, the terms exosomes and ectosomes need to be introduced. Exosomes originate from multivesicular bodies and exocytosis of endocytic bodies, and ectosomes directly originate from the membrane surface $(15,16)$. In this review, we will mainly use the commonly used term "microparticles", keeping in mind their definition as ectosomes $(30,31)$.

MPs display a broad spectrum of bioactive substances and receptors on their surface and harbor a concentrated set of cytokines, signaling proteins, mRNA, and microRNA. Recent studies provided evidence for the concept of MP as veritable vectors for the intercellular exchange of biological signals and information. Indeed, MP may transfer part of their components and content to selected target cells, thus mediating cell activation, phenotypic modification, and reprogramming of cell function. Because MP readily circulate in the vasculature, they may serve as shuttle modules and signaling transducers not only in their local environment but also at remarkable distance from their site of origin. Altogether, this transcellular delivery system may extend the confines of the limited transcriptome and proteome of recipient cells andestablishes a communication network in which specific properties and information among cells can be efficiently shared (22).

Circulating MPs in blood originate from different cells (i.e. red blood cells, granulocytes, monocytes, lymphocytes, platelets and ECs) and their blood levels result from the balance between their rates of release from cells and their clearance from the circulation. Changes in MP levels in circulating blood may be due to some pathological conditions. Platelet - derived MPs (PMPs) are the most abundant, representing about $70-90 \%$ of all circulating MPs (17).

Hence, MP could serve as potential diagnostic markers in laboratory medicine and the development of new diagnostic strategies based on the analysis of number and molecular signature of circulating MP can be anticipated in the near future (32). 


\section{Formation of MPs}

Generation and shedding of MPs occurs during biological processes of considerable diversity, including not only cellular activation following stimulation with proinflammatory, prothrombotic, or proapoptotic substances, or exposure to high shear stress as present in arteries with a severe stenosis, but also cellular differentiation, senescence, or apoptotic cell breakdown $(14,33,34)$.

The plasma membrane is a well-structured entity characterized by a controlled transverse distribution of lipids and proteins between the two leaflets but also by a lateral organization in domains termed "rafts." Following stimulation, a general redistribution occurs, leading to raft structuration, phosphatidylserine externalization, and MP release (10).

In steady-state, the cell membrane is asymmetric regarding the composition and the distribution of phospholipids in its inner and outer layers: phosphatidylcholine and sphingomyelin are located in the outer layer, while phosphatidylserine (PS) and phosphatidyl-ethanolamine (PE) are present in the inner layer. This asymmetric distribution of phospholipids in the membrane is maintained by a three piece enzyme system: flippase, floppase and scramblase. Flippase is an aminophospholipid translocase that specifically translocates PS and PE from the outside to the inside of the bilayer membrane. Floppase transports phospholipids from the inner to the outer leaflet. Floppase does not specifically act on transport of aminophospholipids and probably works together with flippase. Scramblase, whose role is thought to be the transportation of phospholipids between the two monolayers of the cell membrane, is inactive in steady-state $(10,23,35)$.

The exposure of procoagulant phospholipids and the shedding of MPs are cellular responses that depend on activating conditions. Notably, membrane remodeling and PS externalization is dependent on an increase in cytosolic calcium. Activation of human platelets by a $\mathrm{Ca}^{2+}$ ionophore results in the surface exposure of PS. Conversely, the inhibition of $\mathrm{Ca}^{2+}$ influx abolishes agonist-induced PS externalization and the procoagulant response in activated platelets (36).

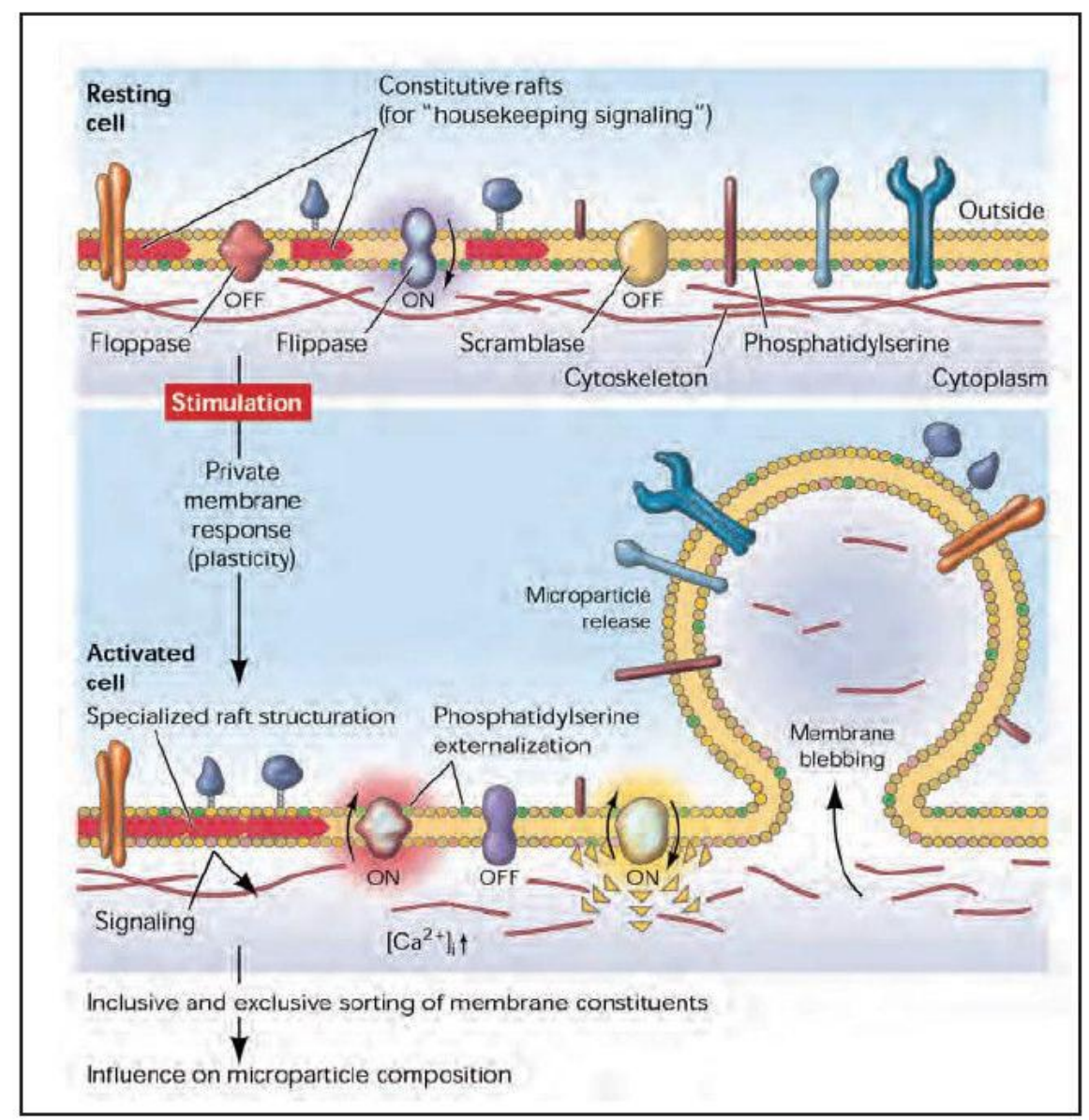

Figure 2. The plasma membrane response to cell stimulation (Adapted with permission from American Physiol Society). 
Calcium inactivates flippase and activates floppase and scramblase, inducing the loss of phospholipids asymmetry between the inner and the outer leaflets. Contacts between aminophospholipids and cytoskeleton are then disrupted. In addition, calcium release leads to activation of two enzymes: calpain and gelsolin. Calpain hydrolyzes actinbinding proteins that decreases association of actin with membranes glycoproteins $(38,39)$, while gelsolin (only in platelets) is involved in the cleavage of the actin capping proteins (40).

As small increases in $\mathrm{Ca}^{2+}$ lead to platelet activation, the maintenance of a stable $\mathrm{Ca}^{2+}$ is essential to keep platelets in a resting state. The mechanisms limiting platelet activation by counteracting $\mathrm{Ca}^{2+}$ leakage from the intracellular stores rely on sarcoplasmic/endoplasmic $\mathrm{Ca}^{2+}$ ATPases that pump the calcium ions back to the stores (targeted by the inhibitor thapsigargin) and on a plasma membrane $\mathrm{Ca}^{2+}$ ATPase that pumps $\mathrm{Ca}^{2+}$ out of the cell $(17,41)$.

When cells undergo activation or apoptosis, PS externalization is one of the earliest observable indicators of the process. Its translocation to the outer leaflet is the initial event that will ultimately lead to the shedding of procoagulant MPs that are therefore regarded as reliable markers of cell stress (42). The dynamic balance of cell stimulation, cell proliferation, and death within the vessels is reflected by the formation and release of MPs that may thus represent a vascular storage pool of bio-effectors (43).

MPs shed from activated, necrotic, or apoptotic cells provide a catalytic phospholipid surface for the assembly of blood coagulation factors, thereby promoting the coagulation cascade and thrombin generation (44). MPs can harbor active tissue factor (TF), the cellular initiator of blood coagulation in vivo (45-47). Because PS and TF are known to act synergistically as potent triggers of blood coagulation, it has been suggested that TF-bearing MPs represent the so-called blood-borne TF (48-50). These observations suggest that MPs can be viewed as a major therapeutic target, not only in the inhibition of arterial and venous thrombosis but also in the containment of the systemic inflammatory response and atherosclerosis (51).

The mechanism of MPs clearance from the circulation is not known. Platelets have a life span of about 10 days, contrasting with that of PMPs of which is about 30 minutes in mice (52), or even less than 10 minutes in rabbits (53). These MPs could be cleared from the circulating blood by phospholipases (54), by direct mechanisms such as PS exposure and subsequent phagocytosis, or by indirect mechanisms such as opsonization by proteins such as growth arrest-specific gene 6 product (GAS6), protein S and complement (55).
A wide variety of methods are used to measure, quantify, and phenotype MPs from blood samples or cell culture supernatants. For this reason, critical evaluation and standardization of the different methods used by each laboratory are necessary to reliably compare studies together. Most methods use flow cytometry although the use of classical flow cytometer is subject to caution, as discussed by Bruce and Barbara C. Furie (56). The small size of MPs enhances the difficulties for their detection and quantification.

MPs can be characterized by the detection of the different cell surface antigens (Table 1). These antigens reflect their origin and activation method.

Despite a recent proteomic characterization of tumoral lymphocyte MPs (57), the chemical composition of MPs remains poorly described. MPs contain various proteins inherited from their parental cells and a membranous skeleton. Thereby, their origin can be identified by the presence of cell-specific surface antigens (Table 1). Other components of MPs have been recently described, such as mRNA $(58,59)$, prions $(60,61)$, contractile proteins such as thrombosthenin (62).

\section{Platelet Microparticles}

Blood contains MPs derived from different cell types, including mainly platelets, but also red blood cells, granulocytes, monocytes, lymphocytes and endothelial cells (ECs). Overproduction of MPs has been related to various physiological and pathophysiological conditions such as cell adhesion, apoptosis, immune response, vascular function, vascular remodeling and angiogenesis, haemostasis and thrombosis, cardiovascular diseases, cancer, infections, as well as normal and pathological pregnancy.

A surface area unit of PMP has approximately 50- to 100 -fold higher procoagulant properties than an identical surface area unit of an activated platelet (63). Thus, the usually accepted role of MPs is to promote coagulation. This is principally due to the presence of TF, the principal initiator of coagulation, exposed on the surface of MPs. Regardless the stimulus, about $25 \%$ of the procoagulant activity in blood is associated with MPs derived from activated platelets (64).

A population of PMPs is generated during platelet activation, whereas other PMPs populations are derived from megakaryocytes during megakaryopoiesis (65-67), quiescent circulating platelets or might result from platelet 
Table 1. Markers for cell-derived MPs

\begin{tabular}{ll}
\hline Cellular origin of MPs & Marker \\
\hline Red blood cell & CD235a \\
Leucocyte & CD45 \\
Granulocyte & CD66b \\
Monocyte & CD14 \\
Lymphocyte & CD4 \\
Platelet & CD8 \\
& CD20 \\
& CD31 \\
& CD41 \\
& CD41a \\
& CD42a \\
CD42b & CD61 \\
CD62P \\
CD31 \\
CD34 \\
CD54 \\
CD62E \\
CD51 \\
CD105 \\
CD106 \\
CD144 \\
CD146 \\
\end{tabular}

apoptosis (52). PMPs can be produced by various stimuli, includingplateletagonists, calciumionophore, complementbinding proteins, or high shear. After stimulation by the thrombin-receptor agonist peptide (TRAP), MPs from 0.1 $\mu \mathrm{m}$ to $1 \mu \mathrm{m}$ and exosomes from 40 to $100 \mathrm{~nm}$ are released (68). Stimulation of platelets activates intracellular calpain, and calpain inhibitors impair MPs release (39).

PMPs are generated under certain blood flow conditions as well (69). High shear stress in severe atherosclerotic arteries activates platelets, generating PMPs, whereas normal shear stress does not (33). In addition, platelet adhesion to immobilized von Willebrand factor (VWF) under fast flow conditions, engages a mechanism for the generation of MPs. This results in the deposition of procoagulant structures that are not removed even under extreme flow conditions, as encountered in severely stenosed arteries (70). This mechanical release of PMPs is dependent on the interaction of $\mathrm{vWf}$ with glycoprotein (GP) Ib $\alpha$, and the resulting procoagulant PMPs enhance thrombus formation (17).

Apoptosis and vascular cell activation are main contributors to the release of procoagulant MPs, deleterious 
partners in atherothrombosis. Elevated levels of circulating platelet, monocyte, or endothelial-derived MPs are associated with most of the cardiovascular risk factors and appear indicative of poor clinical outcome. In addition to being a valuable hallmark of vascular cell damage, MPs are at the crossroad of atherothrombosis processes by exerting direct effects on vascular or blood cells. Under pathological circumstances, circulating MPs would support cellular cross-talk leading to vascular inflammation and tissue remodeling, endothelial dysfunction, leukocyte adhesion, and stimulation. Exposed membrane phosphatidylserine and functional $\mathrm{TF}$ are 2 procoagulant entities conveyed by circulating MPs. At sites of vascular injury, P-selectin exposure by activated endothelial cells or platelets leads to the rapid recruitment of MPs bearing the P-selectin glycoprotein ligand-1 and blood-borne TF, thereby triggering coagulation (44).

\section{Endothelial MPs}

MPs released into the bloodstream can act as messengers delivering a variety of cargos, such as cell surface receptors, proinflammatory cytokines, signaling molecules, and even mRNA, to distal cells $(17,44)$. They may also contribute to disease by transporting viruses and prions $(17,44)$. In addition, in vitro studies have shown that binding of MPs to endothelial cells and monocytes induces the expression of proinflammatory and procoagulant molecules (Figure $3)$.

Inflammation and coagulation are linked processes in many diseases and MPs may amplify the responses by activating the endothelium. In addition, proinflammatory mediators directly induce tissue factor expression in endothelial cells, and the coagulation protease thrombin directly induces the expression of proinflammatory mediators in endothelial cells. This results in elevated levels of endothelial cell-derived MPs, so-called EMPs, in many disease states. The presence of these EMPs in blood can be used as biomarkers of endothelial cell injury $(71,72)$.

EMP $(\sim 100 \mathrm{~nm}$ to $1 \mu \mathrm{m}$ in diameter) result from endothelial plasma membrane blebbing and carry endothelial proteins such as vascular endothelial cadherin, platelet endothelial cell adhesion molecule-1, intercellular cell adhesion molecule (ICAM)-1, endoglin, E-selectin, S-endo or $\alpha v$ integrin (73). Endothelial NO synthase and vascular endothelial growth factor receptor (VEGF-R2) have also been identified on EMP (74), but there is so far no evidence on whether or not MP endothelial nitric oxide synthase is capable of generating nitric oxide; furthermore, endothelial nitric oxide synthase may also be present on platelet or red blood cell-derived MP (75).

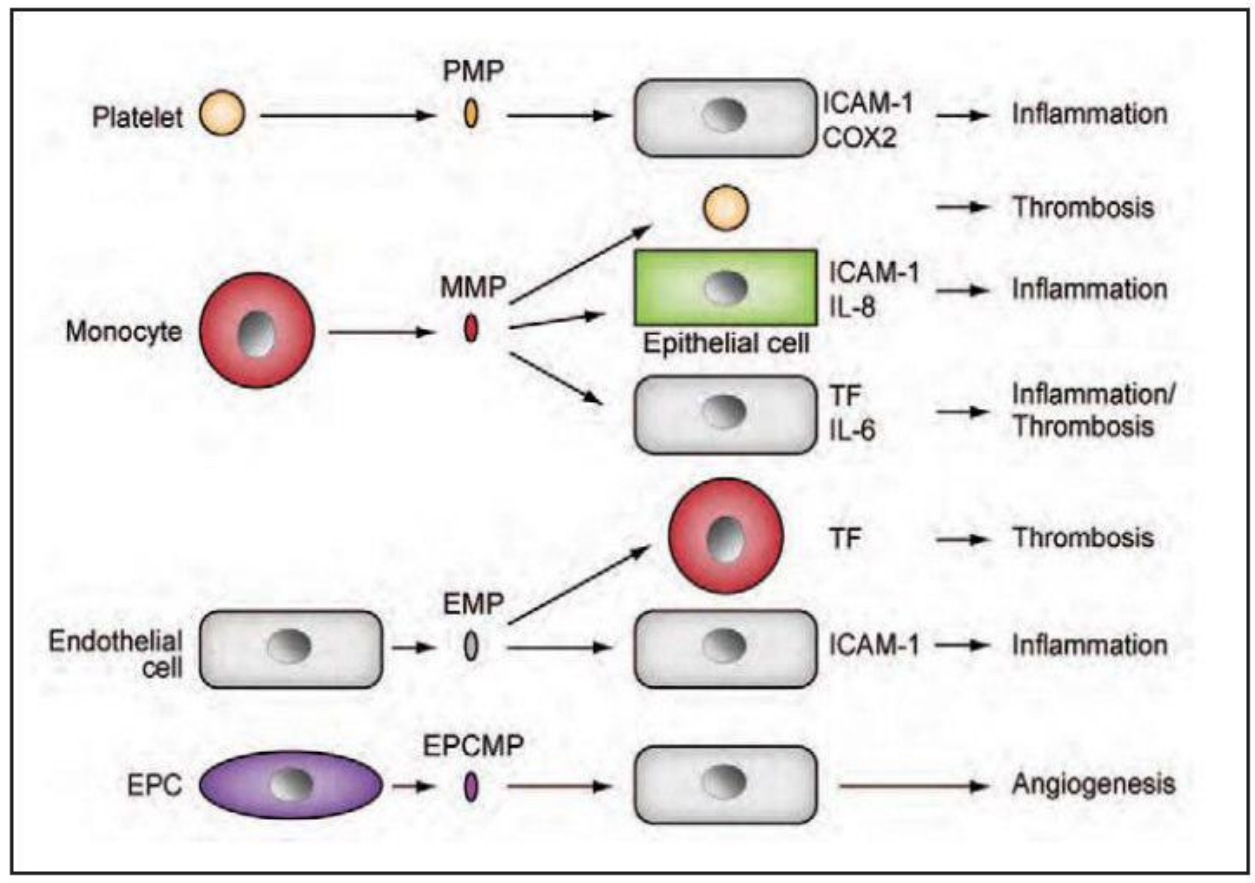

Figure 3. MPs derived from different cell types induce the expression of proinflammatory and procoagulant molecules in endothelial cells, monocytes, and epithelial cells (Adapted with permission from American Heart Asssociation). 


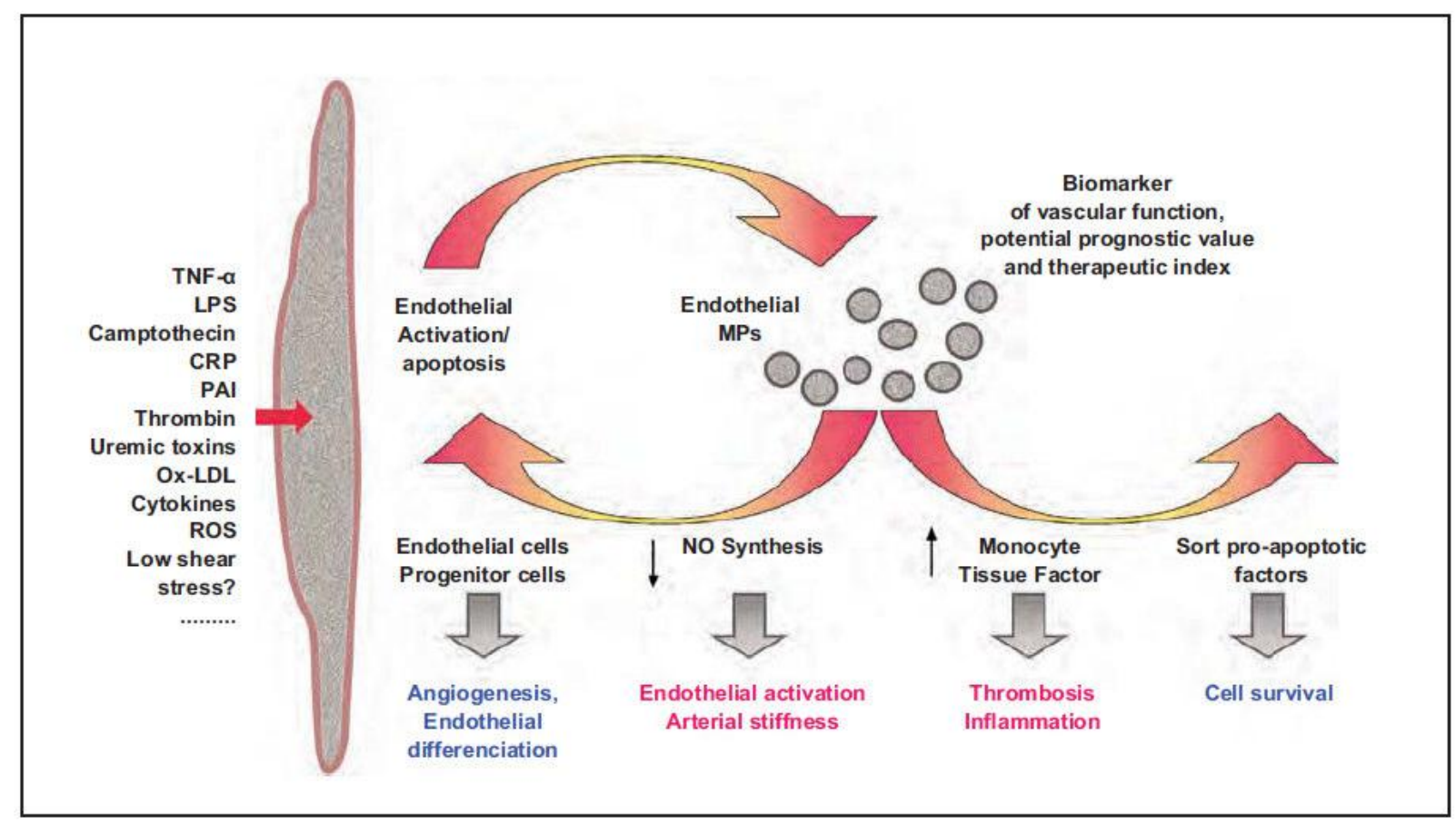

Figure 4. Schematic representation of the different agonists known to augment MP released from cultured endothelial cells and their paradoxical biological functions (Adapted with permission from American Heart Association).

Exosomes $(<100 \mathrm{~nm}$ in diameter) are produced in multivesicular bodies during endocytosis and they play a role in antigen presentation. Unlike MP, they do not externalize PS and they express specific exosomal markers such as Lamp1, CD63, and TSG101; they also contain RNA and microRNAs (21).

Apoptotic bodies are larger than MP or exosomes and are characterized by externalized PS and, unlike MP, a permeable membrane facilitating propidium iodide staining of the nuclear material they contain (76). Several reports indicate that apoptotic bodies are passive cargos delivering their nuclear content (oncogenes, DNA, microRNA) to phagocytes by horizontal transfer $(76,77)$, and thus they share this specific property with EMP (78).

Besides TNF- $\alpha$, other inflammatory cytokines and also bacterial lipopolysaccharides, reactive oxygen species (79), plasminogen activator inhibitor (80), thrombin (81), camptothecin (82), C-reactive protein (CRP) (83), and uremic toxins (84) are able to induce in vitro EMP generation. Interestingly, endogenous nitric oxide dampens the release of EMP on stimulation with CRP by a mechanism involving tetrahydrobiopterin (83).

Although MP of endothelial origin represent a sparse population of circulating MP, changes in their plasma levels might carry important clinical information in healthy subjects and in patients with cardiovascular disorders (73). In patients presenting a characterized endothelial dysfunction, levels of circulating EMP are inversely correlated with the amplitude of flow-mediated dilatation, independently of age and pressure (85-90). Furthermore, acute endothelial injury such as that induced by secondhand smoke rapidly impairs endothelial function and increases circulating EMP in young healthy subjects (91). Therefore, EMP emerge as a new surrogate marker of endothelial health.

So far, only a few studies have investigated the prognostic potential of the measurement of EMP plasma levels. In patients with acute ischemic stroke, EMP levels are associated with lesion volume and clinical outcome, but there was no report about clinical events during follow-up (92). In patients with pulmonary hypertension, circulating levels of EMP expressing E-selectin predict the 1-year outcome (93). In subjects with high risk of coronary heart disease, baseline levels of EMP expressing vascular endothelial cadherin predicted outcome, independently of Framingham score and of CRP and brain natriuretic peptide (BNP) levels (94). Similar findings were observed in chronic renal failure, where high values of $\mathrm{CD} 31^{+} \mathrm{CD} 41^{+}$ EMP were independent predictors of cardiovascular death, whereas other MP plasma subpopulations had no prognostic value (95). These data suggest that EMP levels may be used in the future as a biomarker for stratification of patients and identification of subjects with a high risk of developing cardiovascular complications. Recently, an 
interest in multimarker strategies combining EMP with endothelial progenitor cell levels has emerged from the literature as an integrative marker of vascular health. A change in the ratio of EMP to endothelial progenitor cells may reflect an imbalance between endothelial damage and repair that could be useful to identify patients with damaged vasculature $(96,97)$.

The potential contribution of EMP in endothelial cell survival by showing that EMP release could protect endothelial cell apoptosis by diminishing levels of caspase-3 in cultured endothelial cells resulting from trapping caspase-3 in MP (98). Thus, endothelial-derived MP contribute to the sorting of several proapoptotic factors preventing cell detachment and apoptosis

Finally, EMP carrying endothelial protein $\mathrm{C}$ receptor and activated protein C (APC) could also promote cell survival by induction of cytoprotective and antiinflammatory effects (99).

Taken together, the involvement of EMP in vascular homeostasis appears to be more complex than initially thought. EMP can play a major role in inflammation, thrombosis, and angiogenesis. However, depending on the pathological context, the mechanisms and sites of formation, EMP could have favorable effects to maintain vascular homeostasis. These paradoxical functions might result from EMP composition, as proteomic analysis has shown that one third of the proteins found on EMP are specific to the stimulus initiating their release, not only demonstrating the plasticity of these vesicles but also revealing the complexity of the mechanisms governing their formation (100).

\section{MPs in Angiogenesis}

Angiogenesis is a tightly regulated process that involves endothelial cell survival, proliferation, migration, differentiation, and morphological changes, such as tube formation. It is a major process in many pathological conditions, such as tumor growth, diabetic retinopathy, and inflammation, as well as in embryonic development and wound healing (99).

Most of the research regarding MP has been focused on MP from blood cell origin and on their angiogenic activity, mainly in the tumor microenvironment. However, MP derived from various types of cells, related to other angiogenesis-associated disorders, were found to have angiogenic properties. Submicron membrane vesicles shed from retinal, vascular, and circulating cells were significantly increased in vitreous fluid of patients with proliferative diabetic retinopathy. These MP, isolated from human vitreous sample of patients, were found to stimulate endothelial cell proliferation and formation of new vessels (100).

MP, derived from human circulating endothelial progenitor cells, was shown to activate an angiogenic program in mature quiescent endothelial cells. Endothelial progenitor cell-derived MP expressed several adhesion molecules that were instrumental in MP internalization into endothelial cells and required for their biological activity. The MP-induced antiapoptotic effect organization in capillary-like structures was dependent on mRNA transfer. Also, microarray analysis was pre-formed on MP derived from endothelial progenitor cells, and transcripts associated with the phosphatidylinositol 3-kinase/Akt signaling pathway and with endothelial nitric oxide synthase (known to be involved in the angiogenic and antiapoptotic program) were found (78).

Platelets contain various angiogenesis-related substances that release into the environment upon platelet activation. Moreover, it was recently demonstrated that platelets, as a cellular system, could induce an angiogenic response $(101,102)$. At the same time, platelet activation at sites of blood flow disturbances or endothelium injury results in formation of PMP. Since platelet activation frequently occurs at the sites where angiogenesis takes place (e.g., in the tumor vasculature, or in the proximity of thrombus in an ischemic site), a possible impact of PMP in blood vessel development would be of importance, either as a part of pathogenesis of the malicious processes, or as a counteracting factor.

PMP triggered an angiogenic response, both in vitro and in vivo. This effect is mediated by intra-particle cytokines, i.e., VEGF, bFGF, and PDGF. Separate inhibition of each cytokine resulted in a significant suppression of the vessel sprouting, which suggests that a mutual action of proangiogenic compounds is needed for the development of an angiogenic response (103)

The present study demonstrates for the first time that shed-membrane MPs isolated from human atherosclerotic lesions stimulate endothelial cell proliferation and promote in vivo neo-vessel formation after CD40 ligation. The endothelial proliferative effect of plaque MPs was more pronounced when MPs were isolated from symptomatic patients compared with that seen in asymptomatic patients, and this finding was associated with an increased number of $\mathrm{CD}_{40 \mathrm{~L}^{+}} \mathrm{MPs}$ in these patients. Therefore, accumulation of MPs in atherosclerotic lesions may represent an endogenous signal for atherosclerotic plaque neovascularization and vulnerability (104). 
MPs in Cardiovascular Disease

There are substantial differences between the fractions of MPs or subpopulations in the blood of healthy subjects and those present in patients suffering from diseases with increased thromboembolic risk or vascular damage, such as atherosclerotic vascular disease, sepsis, diabetes, chronic severe hypertension, and preeclampsia $(18,105,106)$. Accordingly, in patients with acute myocardial infarction, elevated numbers of MPs are present compared with healthy controls $(105,106,107)$. Moreover, subtypes of MPs differ between patients with stable angina and those with acute coronary syndromes or myocardial infarction $(108,109)$.

The clinical relevance of the presence of MPs in the blood of healthy subjects is unclear but can be regarded as a reflection of the dynamics of their production by resting, activated, and apoptotic cells and their clearance. In vascular disease states, it remains to be elucidated whether MPs are a cause or a consequence of the condition because disease-related factors, such as infectious agents, cytokines, and metabolic disturbances, are all known to affect the release of MPs $(18,105,106)$.

In cardiovascular disorders, two distinct pools of MPs appear of interest: (1) circulating MPs released from vascular and peripheral blood cells; and (2) MPs shed by apoptotic cells sequestered within the atherosclerotic plaque and eventually exposed to flowing blood after rupture $(110,111)$.

In acute coronary syndromes, TF triggers the formation of intracoronary thrombi following endothelial injury. The acellular lipid-rich core of an atherosclerotic plaque represents its most thrombogenic part (112), with enhanced TF activity being directly supported by $\mathrm{TF}^{+}$-MP exposing PhtdSer.Apoptotic macrophages constitute the main source of membrane-bound TF $(110,113)$. Smooth muscle cells (SMCs) may also contribute to $\mathrm{TF}^{+}$-MPs accumulation in the lipid core. Several mechanisms involving MPs from the plaque could account for instability, as suggested by in vitro data. MP would mediate the recruitment of inflammatory cells within the plaque. Endothelial-derived MPs released on VEGF or FGF2 stimulation harbor functional matrix metalloproteinases possibly favoring fibrous cap proteolysis. In the course of plaque remodeling, MPs of various origin could modulate angiogenesis, a key determinant of plaque vulnerability (114).

MPs may not only have deleterious effects by promoting coagulation and inflammation or by modifying endothelial function, which all contribute to the development of Cardiovascular Disease (CVD); but may also have beneficial effects. First, recent studies have shown that MPs are efficient vectors that exchange biological information between cells (intercellular communication) $(18,105,106)$. Second, the release of MPs protects cells against the consequences of external stimuli or stress. Endothelial cells escape from complement-induced lysis by releasing MPs carrying the lytic complement C5b-9 complex (115). Similarly, the release of MPs protects cells against an overshoot in (internal) cellular reactions triggered by external stressors. Regarding the latter, MPs play a role in "cellular waste management" because they contain increased (compared with parent cell) concentrations of chemotherapeutics, oxidized phospholipids, or caspase 3 $(18,105,106)$.

In patients with subclinical or less occlusive atherosclerosis, more endothelial MPs are present when compared with patients with established or symptomatic atherosclerosis $(109,116)$, suggesting that the ability of the endothelium to release MPs depends on its integrity and viability. In other words, if the ability of the endothelium to release MPs becomes impaired or inhibited, the integrity and viability of the cells may deteriorate.

In vitro, MPs from various cellular or disease origins or both induce endothelial dysfunction, especially by altering the balance between $\mathrm{NO}$ and reactive oxygen species (ROS) production and release (117-119).

Evidently, MPs are able to restore endothelial injury through their dual ability to increase NO and reduce ROS. In summary, MPs can have both detrimental and beneficial effects on endothelial functions, especially by altering the balance between NO and ROS production and release. It seems that these effects are dependent on the specific stimulus underlying the release of MPs by their parent cells.

In the light of the previously described procoagulant and proinflammatory properties of MPs, together with the association between elevated numbers of MPs and clinical CVD, the prevailing view is that circulating MPs are harmful, contributing to CVD and risk of CVD. However, as previously outlined, in addition to their potentially harmful effects, cell-derived MPs may also be beneficial and protect against cellular and vascular damage. Therefore, it is not surprising that both elevated and lower levels of circulating MPs have been associated with (risk factors of) CVD (120).

Interestingly, elevated platelet MPs were described in patients with both type 1 and 2 diabetes, hyperlipidemia, obesity/metabolic syndrome, and hypertension $(18,105)$. 
Thus, in plasma samples from patients with chronic severe hypertension compared with patients with mild hypertension and controls, more MPs exposing platelet endothelial cell adhesion molecule-1 (PECAM-1) (CD31), but not glycoprotein Ib (CD42) (ie, MPs presumably of endothelial or platelet origin or both), were found $(121,122)$. In these patients, elevated numbers of MPs are likely to reflect the cellular stress of endothelial cells and platelets.

Preliminary data indicate that plasma levels of MPs could be of prognostic value for the occurrence of cardiovascular diseases. In a 6-month follow-up study, circulating annexin $\mathrm{V}^{+}$MPs appeared as a robust predictor of the occurrence of secondary myocardial infarction or death in 500 patients with acute coronary syndromes (123). Furthermore, circulating leukocyte-derived MPs, unlike platelet-derived MPs, predict subclinical atherosclerosis burden appreciated by plaque numbers in carotid arteries, abdominal aorta, and femoral arteries in $>200$ asymptomatic subjects (124).

Although the prognostic potential of circulating MPs is still in its infancy, the different studies mentioned above clearly demonstrate that their detection and quantification is an interesting and potentially valuable tool to appreciate

\section{MPs in Cancer}

MPs have been widely detected in various biological fluids including peripheral blood, urine and ascitic fluids, and their function and composition depend on the cells from which they originate. By facilitating the horizontal transfer of bioactive molecules such as proteins, RNAs and microRNAs, they are now thought to have vital roles in tumor invasion and metastases, inflammation, coagulation, and stem-cell renewal and expansion (125).

MP-mediated cargo transfer to adjacent or remote cells has been shown to affect many stages of tumor progression (126), including angiogenesis, escape from immune surveillance, ECM degradation and metastasis (Fig. 5). MPs shed from tumor cells facilitate transfer of soluble proteins (127), nucleic acids (128), functional trans-membrane proteins (129), chemokine receptors (130), tissue factor (129) and receptor tyrosine kinases such as epidermal growth factor receptor (EGFR) and human epidermal growth factor receptor 2 (HER2) $(131,132$ ).

A recent report showed that the oncogenic receptor EGFRvIII, which is found exclusively in a subset of

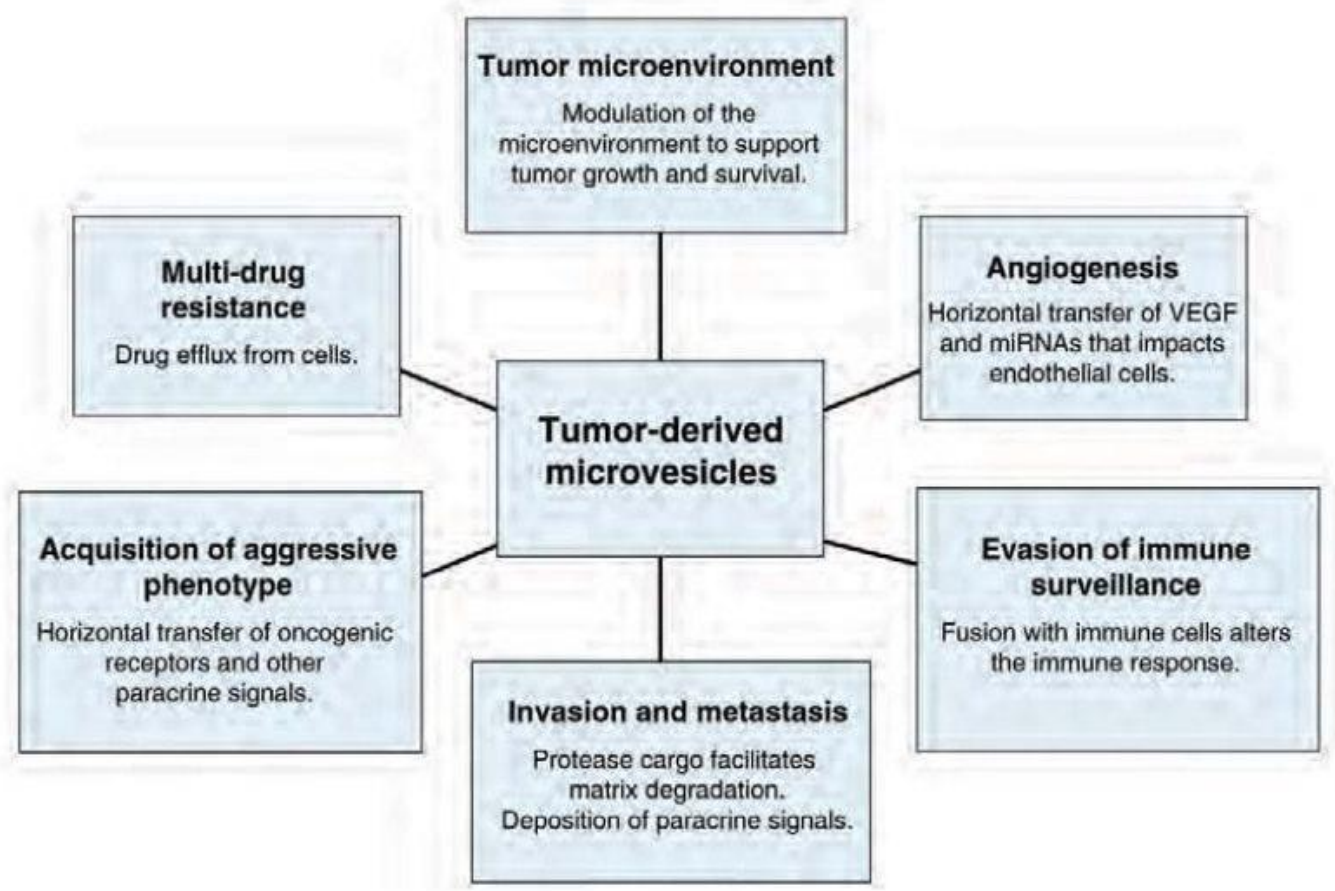

Figure 5. Tumor - derived MPs influence many aspects of cancer progression (Adapted with permission from The Company of Biologists Ltd.). 
aggressive glioma tumors, was transferred to a nonaggressive population of tumor cells through MPs (131). As a consequence, the recipient cells exhibited the activation of two signaling pathways [mitogen-activated protein kinase (MAPK) and Akt] and changes in the expression of EGFRvIII-regulated genes [vascular endothelial growth factor (VEGF), Bcl-Xt, p27], leading to morphological transformation and an increase in anchorage-independent growth.

Thus, MPs secreted by tumor cells induce endothelial cells to release MPs that contain VEGF and sphingomyelin in order to promote angiogenesis. It is interesting that in lung cancer models, hypoxia induces an increased release of MPs (133). Thus, the adverse tumor microenvironment somehow triggers tumor cells to release MPs, which in turn facilitates angiogenesis by bringing nutrients and oxygen to the rescue of cancer cells.

A range of hematological complications broadly categorized as 'thromboembolism' is associated with cancer-related mortality (134). A recent study showed that most of the TF-bearing MPs were tumor derived (135). The group further confirmed the association between the presence of TF-bearing MPs and an increased risk of thromboembolic disease in malignancy (135). Additionally, activation of the coagulation system and TF signaling has also been suggested to deliver growth-promoting stimuli to dormant cancer stem cells (136).

Hypothetically, cancer cells can fuse with MPs derived from non-cancer cells to camouflage behind the lipids and membrane-specific proteins of non-transformed cells. A study by Tesselaar and colleagues identified a low number of circulating MPs from cancer patients that stained for both MUC1, a cancer-cell marker, and glycoprotein IIIa, a protein that is exclusively present on platelets (137). It could be argued that such MPs are released by tumor cells after they have fused with MPs released by platelets. All of the above suggest that the horizontal transfer of MP cargo can successfully divert immune cells to altered phenotypes, thereby facilitating cancer-cell evasion of the immune response.

Matrix degradation is essential for promoting tumor growth and metastasis (138). As indicated above, MPs that are shed by tumor cells are loaded with proteases and provide an additional means of matrix degradation, creating a path of least resistance for invading tumor cells. Accordingly, studies report the presence of Matrix Metalloproteinase (MMP)2, MMP9, MT1-MMP and their zymogens urokinase-type plasminogen activator (uPA) and EMMPRIN, within tumor-derived MPs (139-142). Given the importance of matrix degradation in tumor metastases, it is logical to hypothesize that there is a direct correlation between the number of invasive MPs and tumor progression.

An example for the direct involvement of MPs in facilitating tumor-cell survival comes from the demonstrated expulsion of therapeutic drugs from tumor cells through MPs. Tumor cells treated with doxyrubicin accumulated and released the drug in shed MPs, implying MP shedding as a drug-efflux mechanism involved in drug resistance (143). Another study documented that MPs of cisplatin-insensitive cancer cells contained 2.6- fold more cisplatin than cisplatin-sensitive cells that release MPs (44). Therefore, by virtue of their ability to harness select bioactive molecules and propagate the horizontal transfer of these cargoes, shed MPs can have an enormous impact on tumor growth, survival and spread. Molecules that regulate MP shedding and proteins on circulating MPs that are responsible for tumor growth, progression and survival will be effective targets for anti-cancer therapeutics. Tumor-specific markers that are exposed on circulating MPs might be particularly useful as potential biomarkers. The protein composition of MPs might reflect molecular changes in tumor cells from which they are derived and, therefore, can potentially serve as a prognostic indicator of disease stage and efficacy of treatment.

\section{MPs in Hypertension, Diabetes, and Chronic Renal Failure}

Severe, uncontrolled hypertension is associated with high rates of target organ complications (145-150), but the molecular mechanisms by which extreme blood pressure elevation leads to vascular injury are not well defined. Increasing evidence suggests that hypertension confers a prothrombic state, characterized by abnormalities of endothelial function and platelet activation (151-168). Consequently, investigative interest has recently focused on endothelial and platelet activation as important mediators of hypertensive vascular injury (121).

Endothelial Cells Microparticles (EMP) release can be caused by a number of cytokines such as interleukin-1 and tumor necrosis factor and by elevated shear pressure (169-174). Assays for circulating EMP have recently been developed $(169,170)$ as potential means of quantifying endothelial cell injury.

Platelet derived Microparticles (PMP) concentration is a marker of platelet activation (14,175-176). PMP are formed by platelet membrane vesicle formation and shedding (14). PMP are known to possess procoagulant 
activity and are elevated in severe thrombotic states such as acute myocardial infarction and stroke (14,177-181). EMP and PMP have diverse effects on coagulation, leukocytes, platelets, and endothelium that could ultimately contribute to the pathogenesis of the acute vascular injury observed in patients with uncontrolled severe hypertension. EMP and PMP may therefore be mediators of as well as markers for endothelial and platelet activation and hypertensive target organ injury (121).

Pulmonary arterial hypertension (PAH) is a severe disease of the small pulmonary arteries characterized by vascular narrowing and raised pulmonary artery pressure leading to the development of right-sided heart failure and death. In PAH, vasoconstriction, remodeling of the pulmonary vessel wall, endothelial and vascular smooth muscle cell proliferation and dysfunction, and thrombosis contribute to increased pulmonary vascular resistance (PVR), right ventricle overload, and stretch (182).

Circulating EMPs are increased in chronic renal failure (CRF) and hemodialyzed (HD) patients and represent a new marker of endothelial dysfunction in uremia. In addition, the ability of p-cresol and indoxyl sulfate to increase an EMP release in vitro suggests that the specific-uremic factors could be involved in an EMP elevation in patients $(84,86)$.

Type 2 diabetes is associated with accelerated atherosclerosis $(183,184)$, which is evidenced already early in the course of the disease. Recently, increased numbers of PMP were reported in type 2 diabetic patients with poor metabolic control and microvascular complications (185). TF, possibly of granulocytic origin, is exposed on MP subpopulations in asymptomatic patients with wellregulated type 2 diabetes. TF-positive MPs are associated with components of the metabolic syndrome but not with coagulation. Thus, TF on MPs may be involved in processes other than coagulation, including transcellular signaling or angiogenesis (186).

Compared with age-matched control subjects, type 1 diabetic patients presented significantly higher numbers of platelet and endothelial MPs (PMP and EMP), total annexin V-positive blood cell MPs (TMP), and increased levels of TMP- associated procoagulant activity. In type 2 diabetic patients, only TMP levels were significantly higher without concomitant increase of their procoagulant activity. Interestingly, in type 1 diabetic patients, TMP procoagulant activity was correlated with $\mathrm{HbA1c}$, suggesting that procoagulant activity is associated with glucose imbalance. Thus, diabetic patients differ by the procoagulant activity and the cellular origin of MPs (187).

Endothelial cell dysfunction may contribute to the pathogenesis of multiple sclerosis (MS). Elevations of soluble adhesion molecules intracellular adhesion molecule, vascular cell adhesion molecule, and plateletendothelial cell adhesion molecule-1 (CD31) have been reported as markers of blood-brain barrier (BBB) damage in MS, but direct assay of endothelium has been difficult. Endothelial dysfunction is evident during exacerbation of MS, evidenced by shedding of EMP expressing PECAM-1 (CD31). The in vitro data indicate contribution of one or more plasma factors in endothelial dysfunction of MS (173).

\section{MPs in Stem/Progenitor Cells}

Experimental studies have suggested that transplantation of stem and progenitor cells may have a beneficial effect on functional and structural recovery in several organs, including heart, liver, and kidney. The mechanisms underlining stem-cell therapy are still intensely debated. Some studies have suggested anengraftment of stem cells by transdifferentiation or fusion in targeted organs. However, a growing number of evidences indicate that transient cell localization in the injured tissue may be sufficient to favor functional and regenerative events, suggesting the release of paracrine mediators (188-190). Several mechanisms involved in cell-to-cell communication have been identified, including secretion of growth factors, cytokines, surface receptors, and nucleotides (191-194). It has been suggested that MPs actively released from cells may play an important role in cell-to-cell communication $(6,59,195,196)$.

Embryonic stem cells were recently shown to represent an abundant source of MPs, and it was suggested that MPs derived from these cells may represent one of the critical components supporting self-renewal and expansion of stem Cells $(32,197)$. In addition, Ratajczak et al. (197) demonstrated that embryonic stem cell-derived MPs are able to reprogram hematopoietic progenitors by a horizontal transfer of mRNA and protein delivery.

It has been suggested that transdifferentiation or plasticity of stem cells may at least in part depend on horizontal transfer of mRNA/proteins from the damaged tissue (197). Conversely, MV-mediated transfer of mRNA/proteins derived from stem cells may induce dedifferentiation of mature cells, triggering a proliferative program that may contribute to the repair of tissue injury (52). MP-mediated transfer of $\mathrm{mRNA} /$ proteins derived from stem cells may induce dedifferentiation of mature cells, triggering a proliferative program that may contribute 
to the repair of tissue injury (78). The mechanism by which embryonic stem cell MPs (ESMPs) may mediate intercellular signaling could involve the activation of receptors on the recipient cell by ligands in the ESMP. In this manner, ESMPs would be able to carry membrane bound ligands considerable distances from their stem cell origin. Alternatively, ESMPs may be able to mediate signaling by the direct transfer of proteins, RNA, or bioactive lipids to the recipient cell, serving as "physiological liposomes" $(193,194)$. If ESMPs can indeed serve as "physiological liposomes," transferring RNA and proteins to cells, they can perhaps be used to deliver exogenously expressed genes for therapeutic purposes $(32,197,198)$.

ESMPs are capable of transferring a subset of miRNAs to mouse embryonic fibroblasts (MEFs), suggesting a tightly regulated transfer process. Transfer of miRNAs by MPs represents a novel method of paracrine signaling, potentially making MPs important components of stem cell niches. It also opens up the possibility of transferring siRNAs via MPs (198).

Recently, it has been proposed that a dynamic stem cell regulation may occur as result of differentiated cellstem cell interaction via a MP - based genetic information transfer (25). Progenitor/stem cells may re-direct the behavior of differentiated cells by a horizontal transfer of mRNA shuttled by MPs $(28,197)$ and conversely differentiated cells may influence the stem cell phenotype (25).

Deregibus demonstrated that MPs derived from endothelial progenitor cells may activate an angiogenic program in mature quiescent endothelial cells (78) and that mRNA shuttled by MPs derived from mesenchymal stem cells may induce repair of acute kidney injury (199). Recently, Kostin and Popescu (200) demonstrated that the interstitial cajal-like cells that have been described to be present in the heart (201), communicate with neighbouring cells via shedding of MPs.

Herrera et al. found that MPs derived from human liver stem cells (HLSC) induced in vitro proliferation and apoptosis resistance of human and rat hepatocytes. These effects required internalization of MPs in the hepatocytes by an $\alpha 4$-integrin-dependent mechanism, suggest that MPs derived from HLSC may activate a proliferative program in remnant hepatocytes after hepatectomy by a horizontal transfer of specific mRNA subsets (202).

The ability of MPs to transfer RNA and protein, and to act as paracrine factors raises very exciting possibilities for therapeutic uses. Cells engineered to express mRNA, siRNA, or protein may be capable of delivering these macromolecules to local cellular environments via MPs. These engineered cells can be encapsulated to provide sustained local delivery. Since current techniques for gene transfer use viral or synthetic agents as delivery agents, their replacement by MPs released from autologous transplants of engineered cells will offer the advantage of a virus-free approach and make the prospects of gene therapy safer (198).

\section{Conclusion}

In conclusion, the scientific community has made considerable progress to date in recognizing MP as important mediators of intercellular communication rather than irrelevant cell debris. We have already learned much about the biological effects of MP. Future steps would be to (i) explore their full potential diagnostic application, (ii) develop efficient strategies that will allow us to modulate their secretion in various clinical situations and finally (iii) employ MP as tools to modify the biological responses of cells. A new era of investigation and opportunity for drug development has begun!

\section{References:}

1. Majka M, Janowska-Wieczorek A, Ratajczak J, et al. Numerous growth factors, cytokines, and chemokines are secreted by human CD34(+) cells, myeloblasts, erythroblasts, and megakaryoblasts and regulate normal hematopoiesis in an autocrine/paracrine manner. Blood 2001; 97: 3075-85.

2. Rustom A, Saffrich R, Markovic I, Walther P, Gerdes HH. Nanotubular highways for intercellular organelle transport. Science 2004; 303: 1007-10.

3. Vidulescu C, Clejan S, O'Connor KC. Vesicle traffic through intercellular bridges in DU 145 human prostate cancer cells. J Cell Mol Med 2004; 8: 388-96.

4. Ponsaerts $P$, Berneman ZN. Modulation of cellular behavior by exogenous messenger RNA. Leukemia 2006; 20: 767-9.

5. Haass NK, Herlyn M. Normal human melanocyte homeostasis as a paradigm for understanding melanoma. J Invest Dermatol Symp Proc 2005; 10: 153-63.

6. Morel O, Toti F, Hugel B, Freyssinet JM. Cellularmicroparticles: a disseminated storage pool of bioactive vascular effectors. Curr Opin Hematol 2004; 11: 156-64.

7. Beaudoin AR, Grondin G. Shedding of vesicular material from the cell surface of eukaryotic cells: different cellular phenomena. Bioch Biophys Acta 1991; 1071: 203.

8. Fevrier B, Raposo G. Exosomes: endosomal-derived vesicles shipping extracellular messages. Curr Opin Cell Biol 2004; 16: 415-21.

9. Greenwalt TJ. The how and why of exocytic vesicles. Transfusion 2006; 46: 143-52.

10. Hugel B, Martinez MC, Kunzelmann C, Freyssinet JM. Membrane microparticles: two sides of the coin Physiology (Bethesda) 2005; 20: 22-7.

11. Barry OP, FitzGerald GA. Mechanisms of cellular activation by platelet microparticles. Thromb Haemost 1999; 82: 794-800.

12. Barry OP, Pratico D, Savani RC, FitzGerald GA. Modulation 
of monocyte-endothelial cell interaction by platelet microparticles. J Clin Invest 1998; 102: 136-44.

13. Wolf $P$. The nature and significance of platelet products in human plasma. Br J Haematol. 1967; 13: 269-88.

14. Horstman LL, Ahn YS. Platelet microparticles: a wide-angle perspective. Crit Rev Oncol Hematol. 1999; 30: 111-42.

15. VanWijk MJ, VanBavel E, Sturk A, Nieuwland R. Microparticles in cardiovascular diseases. Cardiovasc Res. 2003; 59: 277-87.

16. George JN, Thoi LL, McManus LM, Reimann TA. Isolation of human platelet membrane microparticles from plasma and serum. Blood. 1982; 60: 834-40.

17. Burnier L, Fontana P, Kwak BR, Angelillo-Scherrer A. Cellderived microparticles in haemostasis and vascular medicine. Thromb Haemost. 2009; 101: 439-51.

18. Nomura S, Ozaki Y, Ikeda Y. Function and role of microparticles in various clinical settings. Thromb Res. 2008; 123: 8-23.

19. Horstman LL, Jy W, Jimenez JJ, Bidot C, Ahn YS. New horizons in the analysis of circulating cell-derived microparticles. Keio J Med 2004; 53: 210-30.

20. Simons M, Raposo G. Exosomes-vesicular carriers for intercellular communication. Curr Opin Cell Biol. 2009; 21: $575-81$.

21. Thery C, Ostrowski M, Segura E. Membrane vesicles as conveyors of immune responses. Nat Rev Immunol. 2009; 9: 581-93.

22. Mause SF, Weber C. Microparticles. Protagonist of a novel communication network for intracellular information exchange. Circ Res 2010; 107: 1047-57.

23. Freyssinet JM. Cellular microparticles: what are they bad or good for? J Thromb Haemost 2003; 1: 1655-62.

24. Quesenberry PJ, Colvin G, Dooner G, et al. The stem cell continuum: cell cycle, injury, and phenotype lability. Ann NY Acad Sci 2007; 1106: 20-9.

25. Quesenberry PJ, Aliotta JM. The paradoxical dynamism of marrow stem cells: considerations of stem cells, niches, and microvesicles. Stem Cell Rev 2008; 4: 137-47.

26. Camussi G, Deregibs MC, Tetta C. Paracrine / endocrine mechanism of stem cells on kidney repair: role of microvesicle - mediated transfer of genetic information. Curr Opin Nephrol Hypertens 2010; 19: 7-12.

27. Jy W, Horstman LL, Jimenez JJ, et al. Measuring circulating cell-derived microparticles. J Thromb Haemost 2004; 2: 1842-1851.

28. Morel O, Morel N, Hugel B, et al. The significance of circulating microparticles in physiology, inflammatory and thrombotic diseases. Rev Med Interne 2005; 26: 791-801.

29. Zwaal RFA, Comfurius P, Bevers EM. Platelet procoagulant activity and microvesicle formation. Its putative role in hemostasis and thrombosis. Biochim Biophys Acta-Mol Basis Dis 1992; 1180: 1-8.

30. Pilzer D, Gasser O, Moskovich O, et al. Emission of membrane vesicles: roles in complement resistance, immunity and cancer. Springer Semin Immunopathol 2005; 27: 37587.

31. Raposo G, Nijman HW, Stoorvogel W, et al. B lymphocytes secrete antigen-presenting vesicles. J Exp Med 1996; 183: 1161-72.

32. Ratajczak J, Wysoczynski M, Hayek F, Janowska - Wieczorek A, Ratajczak MZ. Membrane - derived microvesicles: important and underappreciated mediators of cell - to cell communication. Leukemia 2006; 20: 1487-1495.

33. Holme PA, Orvim U, Hamers MJ, et al. Shear-induced platelet activation and platelet microparticle formation at blood flow conditions as in arteries with a severe stenosis. Arterioscler Thromb Vasc Biol. 1997; 17: 646-53.

34. Vikkula M, Boon LM, Carraway KL III, et al. Vascular dysmorphogenesis caused by an activating mutation in the receptor tyrosine kinase TIE2. Cell. 1996; 87: 118190

35. Valadi H, Ekstrőm K, Bossios A, Sjörtrand M, Lee JJ, Lőtvall JO. Exosome - mediated transfer of mRNAs amd microRNAs is a novel mechanism of genetic exchange between cells. Nat Cell Biol 2007; 9: 654-9.

36. Henseleit U, Plasa G, Haest C. Effects of divalent cations on lipid flip-flop in the human erythrocyte membrane. Biochim Biophys Acta. 1990; 1029: 127-35.
37. Heemskerk JW, Bevers EM, Lindhout T. Platelet activation and blood coagulation. Thromb Haemost. 2002; 88: 18693.

38. Fox JEB, Austin CD, Boyles JK, et al. Role of the membrane skeleton in preventing the shedding of procoagulant-rich microvesicles from the platelet plasma membrane. J Cell Biol 1990; 111: 483-93.

39. Fox JE, Austin CD, Reynolds CC, et al. Evidence that agonistinduced activation of calpain causes the shedding of procoagulant-containing microvesicles from the membrane of aggregating platelets. J Biol Chem 1991; 266: 13289-95.

40. McLaughlin PJ, Gooch JT, Mannherz HG, et al. Structure of gelsolin segment 1-actin complex and the mechanism of filament severing. Nature 1993; 364: 685-92.

41. Morel O, Toti F, Hugel B, Freyssinet JM. Cellular microparticles: a disseminated storage pool of bioactive vascular effectors. Curr Opin Hematol 2004; 11: 156-64.

42. Freyssinet JM, Toti F. Formation of procoagulant microparticles and properties. Thromb Res. 2010; 125(suppl 1):S46S48.

43. Tesse A, Martínez MC, Meziani F, et al. Origin and biological significance of shed-membrane microparticles. Endocr Metab Immune Disord Drug Targets. 2006; 6: 287-94.

44. Morel O, Toti F, Hugel B, et al. Procoagulant microparticles: disrupting the vascularhomeostasis equation? Arterioscler Thromb Vasc Biol. 2006; 26: 2594-2604.

45. Lechner $D$, Weltermann $A$. Circulating tissue factor-exposing microparticles. Thromb Res. 2008; 122(suppl 1): S47S54.

46. Gross PL, Furie BC, Merrill-Skoloff G, Chou J, Furie B. Leukocyteversus microparticle-mediated tissue factor transfer during arteriolar thrombus development. $J$ Leukoc Biol. 2005; 78: 1318-26.

47. Mackman N, Tilley RE, Key NS. Role of the extrinsic pathway of blood coagulation in hemostasis and thrombosis. Arterioscler Thromb Vasc Biol. 2007; 27: 1687-93.

48. Müller I, Klocke A, Alex M, et al. Intravascular tissue factor initiates coagulation via circulating microvesicles and platelets. FASEB J. 2003;17:476-8.

49. Bach R, Rifkin DB. Expression of tissue factor procoagulant activity: regulation by cytosolic calcium. Proc Natl Acad Sci U S A. 1990; 87: 6995-9.

50. Morrissey JH. Tissue factor: an enzyme cofactor and a true receptor. Thromb Haemost. 2001; 86: 66-74.

51. AzevedoLC, PedroMA, LaurindoFR. Circulating microparticles as therapeutic targets in cardiovascular diseases. Recent Pat Cardiovasc Drug Discov. 2007; 2: 41-51.

52. Flaumenhaft R. Formation and fate of platelet microparticles. Blood Cells Mol Dis 2006; 36: 182-7.

53. Rand ML, Wang H, Bang KW, et al. Rapid clearance of procoagulant platelet-derived microparticles from the circulation of rabbits. J Thromb Haemost 2006; 4: 162123.

54. Fourcade O, Simon MF, Viode C, et al. Secretory phospholipase A2 generates the novel lipid mediator lysophosphatidic acid in membrane microvesicles shed from activated cells. Cell 1995; 80: 919-27.

55. Wu Y, Tibrewal N, Birge RB. Phosphatidylserine recognition by phagocytes: a view to a kill. Trends Cell Biol 2006; 16 : 189-197.

56. Furie B, Furie BC. Cancer-associated thrombosis. Blood Cells Mol Dis 2006; 36: 177-81.

57. Miguet L, Pacaud K, Felden C, et al. Proteomic analysis of malignant lymphocyte membrane microparticles using double ionization coverage optimization. Proteomics 2006; 6: 153-71.

58. Fritzsching B, Schwer B, Kartenbeck J, et al. Release and intercellular transfer of cell surface CD81 via microparticles. J Immunol 2002; 169: 5531-7.

59. Baj-Krzyworzeka M, Szatanek R, Weglarczyk K, et al. Tumourderived microvesicles carry several surface determinants and mRNA of tumour cells and transfer some of these determinants to monocytes. Cancer Immunol Immunother 2006; 55: 808-18.

60. Perini F, Vidal R, Ghetti B, et al. PrP27-30 is a normal soluble prion protein fragment released by human platelets. Biochem Biophys Res Commun 1996; 223: 572-7. 
61. Robertson C, Booth SA, Beniac DR, et al. Cellular prion protein is released on exosomes from activated platelets. Blood 2006; 107: 3907-11.

62. Crawford $\mathrm{N}$. The presence of contractile proteins in platelet microparticles isolated from human and animal plateletfree plasma. Br J Haematol 1971; 21: 53-69.

63. Sinauridze El, Kireev DA, Popenko NY, et al. Platelet microparticle membranes have 50 - to 100 -fold higher specific procoagulant activity than activated platelets. Thromb Haemost 2007; 97: 425-34.

64. Tans G, Rosing J, Thomassen MCLGD, et al. Comparison of anticoagulant and procoagulant activities of stimulated platelets and platelet-derived microparticles. Blood 1991; 77: 2641-8.

65. Flaumenhaft R, Dilks JR, Richardson J, et al. Megakaryocytederived microparticles: Direct visualization and distinction from platelet-derived microparticles. Blood 2008; prebub online.

66. Cramer EM, Norol F, Guichard J, et al. Ultrastructure of platelet formation by human megakaryocytes cultured with the Mpl ligand. Blood 1997; 89: 2336-46.

67. Rozmyslowicz T, Majka M, Kijowski J, et al. Platelet-and megakaryocyte-derived microparticles transfer CXCR4 receptor to CXCR4-null cells and make them susceptible to infection by X4-HIV. AIDS 2003; 17: 33-42.

68. Heijnen HF, Schiel AE, Fijnheer R, et al. Activated platelets release two types of membrane vesicles: microvesicles by surface shedding and exosomes derived from exocytosis of multivesicular bodies and alpha-granules. Blood 1999; 94: 3791-9.

69. Miyazaki Y, Nomura S, Miyake T, et al. High shear stress can initiate both platelet aggregation and shedding of procoagulant containing microparticles. Blood 1996; 88: 3456-64.

70. Reininger AJ, Heijnen HF, Schumann $\mathrm{H}$, et al. Mechanism of platelet adhesion to von Willebrand factor and microparticle formation under high shear stress. Blood 2006; 107: 3537-45.

71. Mackman N. On the trail of microparticles. Circ Res 2009; 104: 925-7.

72. Simoncini S, Njock MS, Robert S, et al. TRAIL/Apo2L Mediates the Release of Procoagulant Endothelial Microparticles Induced by Thrombin In Vitro A Potential Mechanism Linking Inflammation and Coagulation. Circ Res. 2009; 104: 943-51.

73. Chironi GN, Boulanger CM, Simon A, Dignat-George F, Freyssinet JM, Tedgui A. Endothelial microparticles in diseases. Cell Tissue Res. 2009; 335: 143-51.

74. Leroyer AS, Ebrahimian TG, Cochain C, Recalde A, BlancBrude O, Mees B, Vilar J, Tedgui A, Levy BI, Chimini G, Boulanger CM, Silvestre JS. Microparticles from ischemic muscle promotes postnatal vasculogenesis. Circulation. 2009; 119: 2808-17.

75. Dignat - George F, Boulanger CM. The many faces of endothelial microparticles. Arterioscler Thromb Vasc Biol 2011; 31: 27-33.

76. Hristov M, ErI W, Linder S, Weber PC. Apoptotic bodies from endothelial cells enhance the number and initiate the differentiation of human endothelial progenitor cells in vitro. Blood. 2004; 104: 2761-6.

77. Bergsmedh A, Szeles A, Henriksson M, et al. Horizontal transfer of oncogenes by uptake of apoptotic bodies. Proc Natl Acad Sci U S A. 2001; 98: 6407-11.

78. Deregibus MC, Cantaluppi V, Calogero R, et al. Endothelial progenitor cell derived microvesicles activate an angiogenic program in endothelial cells by a horizontal transfer of mRNA. Blood. 2007; 110: 2440-8.

79. Szotowski B, Antoniak S, Goldin-Lang P, et al. Antioxidative treatment inhibits the release of thrombogenic tissue factor from irradiation-and cytokine-induced endothelial cells. Cardiovasc Res. 2007; 73: 806-12.

80. Brodsky SV, Malinowski K, Golightly M, Jesty J, Goligorsky MS. Plasminogen activator inhibitor-1 promotes formation of endothelial microparticles with procoagulant potential. Circulation. 2002; 106: 2372-8.

81. Sapet C, Simoncini S, Loriod B, et al. Thrombin-induced endothelial microparticle generation: identification of a novel pathway involving ROCK-II activation by caspase-2. Blood. 2006; 108: 1868-76.
82. Simak J, Holada K, Vostal JG. Release of annexin V-binding membrane microparticles from cultured human umbilical vein endothelial cells after treatment with camptothecin. BMC Cell Biol. 2002; 3: 11.

83. Wang JM, Wang Y, Huang JY, et al. C-Reactive proteininduced endothelial microparticle generation in HUVECs is related to BH4-dependent NO formation. $\mathrm{J}$ Vasc Res. $2007 ; 44: 241-8$.

84. Faure V, Dou L, Sabatier F, et al. Elevation of circulating endothelial microparticles in patients with chronic renal failure. J Thromb Haemost. 2006; 4: 566-73.

85. Koga $\mathrm{H}$, Sugiyama $\mathrm{S}$, Kugiyama $\mathrm{K}$, et al. Elevated levels of VE-cadherin-positive endothelial microparticles in patients with type 2 diabetes mellitus and coronary artery disease. J Am Coll Cardiol. 2005; 45: 1622-30.

86. Amabile N, Guerin AP, Leroyer A, et al. Circulating endothelial microparticles are associated with vascular dysfunction in patients with end-stage renal failure. J Am Soc Nephrol. 2005; 16: 3381-8.

87. Werner N, Wassmann S, Ahlers P, Kosiol S, Nickenig G. Circulating CD31 /annexin V apoptotic microparticles correlate with coronary endothelial function in patients with coronary artery disease. Arterioscler Thromb Vasc Biol. 2006; 26: 112-6.

88. Esposito K, Ciotola Ml, Schisano B, et al. Endothelial microparticles correlate with endothelial dysfunction in obese women. J Clin Endocrinol Metab. 2006; 91: 3676-9.

89. Heiss C, Amabile N, Lee AC, et al. Brief secondhand smoke exposure depresses endothelial progenitor cells activity and endothelial function: sustained vascular injury and blunted nitric oxide production. J Am Coll Cardiol. 2008; 51: $1760-71$.

90. Simak J, Holada K, Risitano AM, Zivny JH, Young NS, Vostal JG. Elevated circulating endothelial membrane microparticles in paroxysmal nocturnal haemoglobinuria. Br J Haematol. 2004; 125: 804-13.

91. Amabile N, Heiss C, Chang V, et al. Increased CD62e(+) endothelial microparticle levels predict poor outcome in pulmonary hypertension patients. J Heart Lung Transplant. 2009; 28: 1081-6.

92. Nozaki T, Sugiyama S, Koga H, et al. Significance of a multiple biomarkers strategy including endothelial dysfunction to improve risk stratification for cardiovascular events in patients at high risk for coronary heart disease. J Am Coll Cardiol. 2009; 54: 601-8.

93. Amabile N, Boulanger CM, Guerin A, Tedgui A, London G. Circulating endothelial microparticles: a novel biomarker for cardiovascular death and cardiovascular events in end-stage-renal disease. Circulation. 2009; 120:S1010S1010.

94. Sabatier F, Camoin-Jau L, Anfosso F, Sampol J, DignatGeorge F. Circulating endothelial cells, microparticles and progenitors: key players towards the definition of vascular competence. J Cell Mol Med. 2009; 13: 454-71.

95. Pirro M, Schillaci G, Paltriccia R, et al. Increased ratio of CD31/CD42-microparticles to endothelial progenitors as a novel marker of atherosclerosis in hypercholesterolemia. Arterioscler Thromb Vasc Biol. 2006; 26: 2530-5.

96. Abid Hussein MN, Boing AN, Sturk A, Hau CM, Nieuwland R. Inhibition of microparticle release triggers endothelial cell apoptosis and detachment. Thromb Haemost. 2007; 98 : 1096-107.

97. Perez-Casal M, Downey C, Cutillas-Moreno B, Zuzel M, Fukudome K, Toh CH.Microparticle-associatedendothelial protein $\mathrm{C}$ receptor and the induction of cytoprotective and anti-inflammatory effects. Haematologica. 2009; 94 : 38794.

98. Peterson DB, Sander T, Kaul S, et al. Comparative proteomic analysis of PAL-1 and TNF-a-derived endothelial microparticles. Proteomics. 2008; 8: 2430-2446.

99. Folkman J. Angiogenesis and apoptosis. Semin Cancer Biol. 2003; 13: 159-67.

100. Shai E, Varon D. Development, cell differentiation, angiogenesis-microparticles and their roles in angiogenesis. Arterioscler Thromb Vasc Biol 2011; 31: $10-14$.

101. Brill A, Elinav H, Varon D. Differential role of platelet granular mediators in angiogenesis. Cardiovasc Res 2004; 63 : 226-35. 
102. Rhee JS, Black M, Schubert U, et al. The functional role of blood platelet components in angiogenesis. Thromb Haemost 2004; 92: 394-402

103. Brill A, Dashevsky O, Rivo J, Gozal Y, Varon D. Platelet derived microparticles induce angiogenesis and stimulate post - ischemic revascularization. Cardiovasc Res 2005; 67: 30-8.

104. Leroyer AS, Rautou PE, Silvestre JS, et al. CD40 Ligand+ microparticles from human atherosclerotic plaques stimulate endothelial proliferation and angiogenesis. $J$ Am Coll Cardiol 2008; 52: 1302-11.

105. Diamant M, Tushuizen ME, Sturk A, Nieuwland $R$. Microparticles: new players in the field of vascular disease? Eur J Clin Invest. 2004; 34: 392-401.

106. Boulanger CM, Amabile N, TedguiA. Circulating microparticles: a potential prognostic marker for atherosclerotic vascular disease. Hypertension. 2006; 48:180-6.

107. Van der Zee PM, Biro' E, Ko Y, et al. P-selectin- and CD63exposing platelet microparticles reflect platelet activation in peripheral arterial disease and myocardial infarction. Clin Chem. 2006; 52: 657-64.

108. Bernal-Mizrachi L, Jy W, Jimenez JJ, Pastor J, et al. High levels of circulating endothelial microparticles in patients with acute coronary syndromes. Am Heart J. 2003; 145 : 962-70.

109. Bernal-Mizrachi L, Jy W, Fierro C, et al. Endothelial microparticles correlate with high-risk angiographic lesions in acute coronary syndromes. Int J Cardiol. 2004 97: $439-46$.

110. Mallat Z, Hugel B, Ohan J, Leseche G, Freyssinet JM, Tedgui A. Shed membrane microparticles with procoagulant potential in human atherosclerotic plaques: a role for apoptosis in plaque thrombogenicity. Circulation. 1999 99: 348-53.

111. Bonderman D, Teml A, Jakowitsch J, et al. Coronary noreflow is caused by shedding of active tissue factor from dissected atherosclerotic plaque. Blood. 2002; 99: 2794 -2800 .

112. Toschi V, Gallo R, Lettino M, et al. Tissue factor modulates the thrombogenicity of human atherosclerotic plaques. Circulation. 1997; 95: 594-9.

113. Taraboletti G, D'Ascenzo S, Borsotti P, Giavazzi R, Pavan A, Dolo V. Shedding of the matrix metalloproteinases matrixmetalloproteinase (MMP)-2, MMP-9, and MT1MMP as membrane vesicle-associated components by endothelial cells. Am J Pathol. 2002; 160: 673-80.

114. Virmani R, Kolodgie FD, Burke AP, et al. Atherosclerotic plaque progression and vulnerability to rupture: angiogenesis as a source of intraplaque hemorrhage. Arterioscler Thromb Vasc Biol. 2005; 25: 2054-61.

115. Sims PJ, Wiedmer T. Induction of cellular procoagulant activity by the membrane attack complex of complement. Semin Cell Biol. 1995; 6: 275-82.

116. Philippova M, Suter $\mathrm{Y}$, Toggweiler $\mathrm{S}$, et al. T-cadherin is present on endothelial microparticles and is elevated in plasma in early atherosclerosis. Eur Heart J. 2010; 32: 760-1.

117. Brodsky SV, Zhang F, Nasjletti A, Goligorsky MS. Endotheliumderived microparticles impair endothelial function in vitro. Am J Physiol Heart Circ Physiol. 2004; 286: H1910H15.

118. VanWijk MJ, Svedas E, Boer K, Nieuwland R, VanBavel E, Kublickiene KR. Isolated microparticles, but not whole plasma, from women with preeclampsia impair endothelium-dependent relaxation in isolated myometria arteries from healthy pregnant women. Am J Obstet Gynaecol. 2002; 187: 450-56.

119. Mostefai HA, Agouni A, Carusio N, et al. Phosphatidylinositol 3-kinase and xanthine oxidase regulate nitric oxide and reactive oxygen species productions by apoptotic lymphocyte microparticles in endothelial cells. J Immunol. 2008; 180: 5028-35.

120. Tushuizen ME, Diamant M, SturkA, Nieuwland R. Cell-derived microparticles in the pathogenesis of cardiovascular disease. Friend or foe? Arterioscler Thromb Vasc Biol 2011; 31: 4-9.

121. Preston RA, Jy W, Jimenez JJ, et al. Effects of severe hypertension on endothelial and platelet microparticles. Hypertension. 2003; 41: 211-7.
122. Pirro M, Schillaci G, Bagaglia F, et al. Microparticles derived from endothelial progenitor cells in patients at different cardiovascular risk. Atherosclerosis. 2008; 197: 757-67.

123. Mallat Z, Steg PG, Hugel B, et al. Prognostic value of circulating shed membrane pro-coagulant microparticles in patients with severe acute coronary syndromes. A substudy from the global registry of acute coronary events (GRACE). Circulation. 2004; 110(Suppl S): 575. Abstract.

124. Chironi G, Hugel B, Bihorel $\mathrm{Y}$, et al. Leukocyte-derived microparticles as an independent marker of preclinical carotid atherosclerosis. Circulation. 2005; 112: U126. Abstract.

125. Muralidharan - Chari V, Clancy JW, Sedgwick A, D'Souza - Schorey C. Microvesicles: mediators of extracellular communication during cancer progression. J Cell Sci 2010; 123: 1603-11.

126. van Doormaal, FF, Kleinjan A, Di Nisio M, Buller HR, Nieuwland R. Cell-derived microvesicles and cancer. Neth. J. Med. 2009; 67: 266-73.

127. lero $M$, Valenti $R$, Huber $V$, et al. Tumour-released exosomes and their implications in cancer immunity. Cell Death Differ. 2008; 15: 80-8.

128. Skog J, Wurdinger T, van Rijn S, et al. Glioblastoma microvesicles transport RNA and proteins that promote tumour growth and provide diagnostic biomarkers. Nat. Cell Biol. 2008; 10: 1470-6.

129. Del Conde I, Shrimpton CN, Thiagarajan P, Lopez JA. Tissuefactor-bearing microvesicles arise from lipid rafts and fuse with activated platelets to initiate coagulation. Blood 2005; 106: 1604-11.

130. Mack M, Kleinschmidt A Bruhl $\mathrm{H}$, et al. Transfer of the chemokine receptor CCR5 between cells by membranederived microparticles: a mechanism for cellular human immunodeficiency virus 1 infection. Nat. Med. 2000; 6: 769-75.

131. Al-Nedawi K, Meehan B, Micallef J, et al. Intercellular transfer of the oncogenic receptor EGFRvIII by microvesicles derived from tumour cells. Nat. Cell Biol. 2008; 10: 61924.

132. Sanderson MP, Keller S, Alonso A, Riedle S, Dempsey PJ, Altevogt P. Generation of novel, secreted epidermal growth factor receptor (EGFR/ErbB1) isoforms via metalloprotease-dependent ectodomain shedding and exosome secretion. J. Cell Biochem. 2008; 103: 17831797.

133. Wysoczynski M, Ratajczak MZ. Lung cancer secreted microvesicles: underappreciated modulators of microenvironment in expanding tumors. Int. J. Cancer 2009; 125: 1595-1603.

134. Zwicker JI, Furie BC, Furie B. Cancer-associated thrombosis. Crit. Rev. Oncol. Hematol. 2007; 62: 126-36.

135. Zwicker JI, Liebman HA, Neuberg D, et al. Tumor-derived tissue factor-bearing microparticles are associated with venous thromboembolic events in malignancy. Clin. Cancer Res. 2009; 15: 6830-40.

136. Milsom C, Yu J, May L, Meehan B., et al. The role of tumorand host-related tissue factor pools in oncogene-driven tumor progression. Thromb. Res. 2007; 120: S82-S91.

137. Tesselaar ME, Romijn FP, Van Der Linden IK, Prins FA, Bertina RM, Osanto S. Microparticle-associated tissue factor activity: a link between cancer and thrombosis? J. Thromb. Haemost. 2007; 5: 520-7.

138. Hotary K, Li XY, Allen E, Stevens SL, Weiss SJ. A cancer cell metalloprotease triad regulates the basement membrane transmigration program. Genes Dev.2006; 20: 26732686.

139. Angelucci A, D'Ascenzo S, Festuccia C, et al. Vesicleassociated urokinase plasminogen activator promotes invasion in prostate cancer cell lines. Clin. Exp. Metastasis 2000; 18: 163-170.

140. Ginestra A, La Placa MD, Saladino F, Cassara D, Nagase $\mathrm{H}$, Vittorelli ML. The amount and proteolytic content of vesicles shed by human cancer cell lines correlates with their in vitro invasiveness. Anticancer Res. 1998; 18: 3433-7.

141. Baj-Krzyworzeka M, Szatanek R, Weglarczyk K, et al. Tumour-derived microvesicles carry several surface determinants and mRNA of tumour cells and transfer some of these determinants to monocytes. Cancer Immunol. Immunother. 2006; 55: 808-18. 
142. Hakulinen J, Sankkila L. Sugiyama N, Lehti K, KeskiOja J. Secretion of active membrane type 1 matrix metalloproteinase (MMP-14) into extracellular space in microvesicular exosomes. J. Cell Biochem. 2008; 105: 1211-8.

143. Shedden K, Xie XT, Chandaroy P, Chang YT, Rosania GR. Expulsion of small molecules in vesicles shed by cancer cells: association with gene expression and chemosensitivity profiles. Cancer Res. 2003; 63: 4331-7.

144. Safaei R, Larson BJ, Cheng TC, et al. Abnormal lysosomal trafficking and enhanced exosomal export of cisplatin in drug-resistant human ovarian carcinoma cells. Mol. Cancer Ther. 2005; 4: 1595-1604.

145. Joint National Committee on Prevention, Detection, Evaluation, and Treatment of High Blood Pressure. The sixth report of the Joint National Committee on Prevention, Detection, Evaluation and Treatment of High Blood Pressure (JNC VI). Arch Intern Med. 1997; 157: 2413-44.

146. 1999 World Health Organization. International Society of Hypertension, Guidelines for the Management of Hypertension: guidelines subcommittee. J Hypertens. 1999; 17: 151-83.

147. Kaplan N. Hypertensive crises. In: Kaplan N. Clinical Hypertension. 7th ed. Baltimore, Md: Williams and Wilkins; 1998: 265-80.

148. Veterans Administration Cooperative Study Group on Antihypertensive Agents. Effects of treatment on morbidity in hypertension: results in patients with diastolic blood pressure averaging 115-129 mm Hg. JAMA. 1967; 202: 116-22.

149. Preston RA, Baltodano NM, Cienki J, Materson BJ. Clinical presentation and management of patients with uncontrolled, severe hypertension: results from a public teaching hospital. J Hum Hypertens. 1999; 13: 249-55.

150. Preston RA, Materson BJ, Yoham MA, Anapol H. Hypertension in Haitians: pilot survey of a public teaching hospital multispecialty clinic. J Hum Hypertens. 1996; 10: 743-5.

151. Ross R. Atherosclerosis: an inflammatory disease. N Engl J Med. 1999; 340: 115-26.

152. Lip GY, Blann AD. Does hypertension confer a prothrombotic state? Virchow's triad revisited. Circulation. 2000; 101: 218-20.

153. Lip GYH, Blann AD, Beevers DG. Prothrombotic factors, endothelial function and left ventricular hypertrophy in isolated systolic hypertension compared with systolicdiastolic hypertension. J Hypertens. 1999; 17: 1203-7.

154. Ferri C, Bellini C, Desideri G, Giuliani et al. Clustering of endothelial markers of vascular damage in human saltsensitive hypertension: influence of dietary sodium load and depletion. Hypertension. 1998; 32: 862-8.

155. Ferri C, Desideri G, Valenti M, et al. Early upregulation of endothelial adhesion molecules in obese hypertensive men. Hypertension. 1999; 34: 568-73.

156. Lip GYH, Edmunds E, Hee FLLS, Blann AD, Beevers DG. A crosssectional, diurnal, and follow-up study of platelet activation and endothelial dysfunction in malignant phase hypertension. Am J Hypertens. 2001; 14: 823-8.

157. John S, Schmieder RE. Impaired endothelial function in arterial hypertension and hypercholesterolemia: potential mechanisms and differences J Hypertens. 2000; 18 363-74.

158. Park JB, Charbonneauc F, Schiffrin EL. Correlation of endothelial function in large and small arteries in human essential hypertension. J Hypertens. 2001; 19: 415-20.

159. Rizzoni D, Porteri E, Guelfi D, et al. Endothelial dysfunction in small resistance arteries of patients with non-insulindependent diabetes mellitus. J Hypertens. 2001; 19: 913-9.

160. Vanhoutte PM. How to assess endothelial function in human blood vessels. J Hypertens. 1999; 17: 1047-58.

161. Camilletti A, Moretti N, Giacchetti G, et al. Decreased nitric oxide levels and increased calcium content in platelets of hypertensive patients. Am J Hypertens. 2001; 14 382-6.

162. Blann AD, Lip GY, Islim IF, Beevers DG. Evidence of platelet activation in hypertension. J Hum Hypertens. 1997;11: 607-9.

163. Riondino S, Pignatelli P, Pulcinelli FM, et al. Platelet hyperactivity in hypertensive older patients is controlled by lowering blood pressure. J Am Geriatr Soc. 1999; 47: 943-7.

164. Verhaar MC, Beutler JJ, Gaillard CA, Koomans HA Fijnheer R, Rabelink TJ. Progressive vascular damage in hypertension is associated with increased levels of circulating P-selectin. J Hypertens. 1998;16: 45-50.

165. Tomoda F, Takata M, Kagitani S, et al. Different platelet aggregability during mental stress in two stages of essential hypertension. Am J Hypertens. 1999; 12: 106370.

166. Dockrell ME. Walker BR. Noon JP. Watt GC. Williams BC. Webb DJ. Platelet aggregation in young men with contrasting predisposition to high blood pressure. Am J Hypertens. 1999; 12: 115-9.

167. Davi G, Gresele P, Violi F, et al. Diabetes mellitus, hypercholesterolemia, and hypertension but not vascular disease per se are associated with persistent platelet activation in vivo. Evidence derived from the study of peripheral arterial disease. Circulation. 1997; 96: 69-75.

168. Cadwgan TM, Benjamin N. Evidence for altered platelet nitric oxide synthesis in essential hypertension. J Hypertens. 1993; 11: 417-20.

169. Combes V, Simon A-C, Grau G-E, et al. In vitro generation of endothelial microparticles and possible prothrombotic activity in patients with lupus anticoagulant. J Clin Invest. 1999; 104: 93-102.

170. Jimenez JJ, Jy W, Mauro LM, Horstman LL, Ahn YS. Elevated endothelial microparticles in thrombotic thrombocytopenic purpura: findings from brain and renal microvascular cell culture and patients with active disease. $\mathrm{Br} \mathrm{J}$ Haematol. 2001; 112: 81-90.

171. Mallat Z, Benamer H, Hugel B, et al. Elevated levels of shed membrane microparticles with procoagulant potential in the peripheral circulating blood of patients with acute coronary syndromes. Circulation. 2000; 101: 841-43.

172. Larkin M. Raised endothelial microparticles an early marker for multiple sclerosis? Lancet. 2001; 357: 1679.

173. Minagar A, Jy W, Jimenez JJ, et al. Elevated plasma endothelial microparticles in multiple sclerosis. Neurology. 2001; 56: 1319-24.

174. Boulanger CM, Scoazec A, Ebrahimian T, et al. Circulating microparticles from patients with myocardial infarction cause endothelial dysfunction. Circulation. 2001;104: 2649-52.

175. Horstman LL, Ahn YS. Platelet microparticles: a wide-angle perspective. Crit Rev Oncol/Hematol. 1999; 30: 111-42.

176. Tocchetti EV, Flower RL, Lloyd JV. Assessment of in vitrogenerated platelet microparticles using a modified flow cytometric strategy. Thromb Res. 2001; 103: 47-55.

177. Nomura S, Nakamura T, Cone J, Tandon NN, Kambayashi J. Cytometric analysis of high shear-induced platelet microparticles and effect of cytokines on microparticle generation. Cytometry. 2000; 40: 173-81.

178. Lee YJ, Jy W, Horstman LL, et al. Elevated platelet microparticles in transient ischemic attacks, lacunar infarcts, and multiinfarct dementias. Thromb Res. 1993; 72: 295-304.

179. Geiser T, Sturzenegger M, Genewein U, Haeberli A, Beer JH. Mechanisms of cerebrovascular events as assessed by procoagulant activity, cerebral microemboli, and platelet microparticles in patients with prosthetic heart valves. Stroke. 1998; 29: 1770-7

180. Katopodis JN, Kolodny L, Jy W, et al. Platelet microparticles and calcium homeostasis in acute coronary ischemias. Am J Hematol. 1997; 54: 95-101.

181. Jy W, Horstman LL, Arce M, Ahn YS. Clinical significance of platelet microparticles in autoimmune thrombocytopenias. J Lab Clin Med. 1992; 119: 334-345.

182. Bakouboula B, Morel O, Faure A, et al. Procoagulant membrane microparticles correlate with the severity of pulmonary arterial hypertension. Am J Crit Care Med 2008; 177: 536-43.

183. Kannel WB, McGee DL. Diabetes and cardiovascular risk factors: the Framingham Study. Circulation. 1979; 59: $8-13$.

184. Stamler J, Vaccaro O, Neaton JD, et al. Diabetes, other risk factors and 12-year cardiovascular mortality for men screened in the Multiple Risk Factor Intervention Trial. 
Diabetes Care. 1993; 16: 434-44.

185. Omoto S, Nomura S, Shouzu A, et al. Significance of plateletderived microparticles and activated platelets in diabetic nephropathy. Nephron. 1999; 81: 271-7.

186. Diamant M, Nieuwland R, Pablo RF, et al. Elevated numbers of tissue - factor exposing microparticles correlate with components of the metabolic syndrome in uncomplicated type 2 diabetes mellitus. Circulation 2001; 106: 244247.

187. Sabatier F, Darmon P, Hugel B, et al. Type 1 and Type 2 diabetic patients display different patterns of cellular microparticles. Diabetes 2002; 51: 2840-5.

188. Wollert KC, Drexler H. Mesenchymal stem cells for myocardial infarction: promises and pitfalls. Circulation. 2005; 112: 151-3.

189. Fiegel $\mathrm{HC}$, Lange $\mathrm{C}$, Kneser $\mathrm{U}$, et al. Fetal and adult liver stem cells for liver regeneration and tissue engineering. J. Cell Mol Med. 2006; 10: 577-87.

190. Cantley LG. Adult stem cells in the repair of the injured renal tubule. Nat Clin Pract Nephrol. 2005; 1: 22-32.

191. Levine SJ. Mechanisms of soluble cytokine receptor generation. J Immunol. 2004; 173: 5343-8.

192. Lucas WJ, Yoo BC, Kragler F. RNA as a long-distance information macromolecule in plants. Nat Rev Mol Cell Biol. 2001; 2: 849-57.

193. Albi E, Viola Magni MP. The role of intranuclear lipids. Biol Cell. 2004; 96: 657-67.

194. Taback B, Hoon DS. Circulating nucleic acids and proteomics of plasma/serum: clinical utility. Ann N Y Acad Sci. 2004; 1022: $1-8$.

195. Janowska-Wieczorek A, Majka M, Kijowski J, et al. Plateletderived microparticles bind to hematopoietic progenitor cells and enhance their engraftment. Blood. 2001; 98: 3143-9.

196. Christian JL. Argosomes: intracellular transport vehicles for intercellular signals? Sci STKE. 2002; 2002(124):PE13.

197. Ratajczak J, Miekus K, Kucia M, et al. Embryonic stem cell-derived microvesicles reprogram hematopoietic progenitors: evidence for horizontal transfer of mRNA and protein delivery. Leukemia. 2006; 20: 847-56.

198. Yuan A, Farber EL, Rapoport AL, et al. Transfer of MicroRNAs by embryonic stem cell microvesicles. Plos One 2009; 4: e4722.

199. Bruno S, Grange C, Deregibus MC et al. Human mesenchymal stem cell-derived microvesicles protect against acute tubular injury. J Am Soc Nephrol. 2009; 20: 1053-67.

200. Kostin S, Popescu LM. A distinct type of cell in myocardium: interstitial Cajal-like cells. J Cell Mol Med. 2009; 13: 295308.

201. Hinescu ME, Popescu LM. Interstitial Cajal-like cells (ICLC) in human atrial myocardium. J Cell Mol Med. 2005; 9: 972-5.

202. Herrera MB, Fonsato V, Gatti S, et al. Human liver stem cell derived microvesicles accelerate hepatic regeneration in hepatectomized rats. J Cell Mol Med 2010; 14: 1605-18. 